\title{
Pore-Scale Process Coupling and Effective Surface Reaction Rates in Heterogeneous Subsurface Materials
}

\author{
Chongxuan Liu, Yuanyuan Liu, \\ Sebastien Kerisit and John Zachara \\ Pacific Northwest National Laboratory \\ Richland, Washington, USA \\ Chongxuan.liu@pnnl.gov
}

\section{INTRODUCTION}

Heterogeneity in pore structure and reaction properties including grain size and mineralogy, pore size and connectivity, and sediment surface area and reactivity is a common phenomenon in subsurface materials. Heterogeneity affects transport, mixing, and the interactions of reactants that affect local and overall geochemical and biogeochemical reactions. Effective reaction rates can be orders of magnitude lower in heterogeneous porous media than those observed in well-mixed, homogeneous systems as a result of the pore-scale variability in physical, chemical, and biological properties, and the coupling of pore-scale surface reactions with mass-transport processes in heterogeneous materials.

Extensive research has been performed on surface reactions at the pore-scale to provide physicochemical insights on factors that control macroscopic reaction kinetics in porous media. Mineral dissolution and precipitation reactions have been frequently investigated to evaluate how intrinsic reaction rates and mass transfer control macroscopic reaction rates. Examples include the dissolution and/or precipitation of calcite (Bernard 2005; Li et al. 2008; Tartakovsky et al. 2008a; Flukiger and Bernard 2009; Luquot and Gouze 2009; Kang et al. 2010; Zhang et al. 2010a; Molins et al. 2012, 2014; Yoon et al. 2012; Steefel et al. 2013; Luquot et al. 2014), anorthite and kaolinite (Li et al. 2006, 2007), iron oxides (Pallud et al. 2010a,b; Raoof et al. 2013; Zhang et al. 2013a), and uranyl silicate and uraninite (Liu et al. 2006; Pearce et al. 2012). Adsorption and desorption at the pore-scale have been investigated to understand the effect of pore structure heterogeneity on reaction rates and rate scaling from the pore to macroscopic scales (Acharya et al. 2005; Zhang et al. 2008, 2010c, 2013b; Zhang and Lv 2009; Liu et al. 2013a). Microbially mediated reactions have also been studied at the pore-scale including denitrification (Raoof et al. 2013; Kessler et al. 2014), sulfate reduction (Raoof et al. 2013), organic matter and nutrient transformation (Knutson et al. 2007; Gharasoo et al. 2012; Raoof et al. 2013), and biomass growth (Dupin and McCarty 2000; Dupin et al. 2001; Nambi et al. 2003; Knutson et al. 2005; Zhang et al. 2010b; Tartakovsky et al. 2013). These studies indicate that pore-scale heterogeneity and coupling of reaction and transport have major impacts on the macroscopic manifestation of reactions and reaction rates.

Various experimental and numerical approaches have been developed and applied for pore-scale investigation of surface reactions in porous media. A micromodel is one of the experimental systems most widely used for studying pore-scale reactions under flow conditions. It is a 2-dimensional (2-D) flow cell system typically fabricated with silicon materials, into which a desired pore structure can be imprinted to form a pore network (Zhang et al. 2010a). The interfaces between pores and solids in the pore network can be coated with certain redoxsensitive materials such as hematite (Zhang et al. 2013a) to provide reactive sites for surface 
reactions. The micromodel allows real time observation of surface reactions at the pore-scale using a suite of spectroscopic and microscopic techniques including optical microscopy (Dupin and McCarty 2000; Nambi et al. 2003; Knutson et al. 2005; Zhang et al. 2010a; Yoon et al. 2012), synchrotron X-ray microprobe (XMP) and X-ray absorption spectroscopy (XAS) (Pearce et al. 2012), and Raman spectroscopy (Zhang et al. 2013a). Other experimental systems for pore-scale research include flow-cell reactors (Fredd and Fogler 1998; Panga et al. 2005; Pallud et al. 2010a,b), capillary tubes (Molins et al. 2014), and columns (Bernard 2005; Luquot and Gouze 2009; Fridjonsson et al. 2011; Noiriel et al. 2012; Luquot et al. 2014). These experimental apparatus complemented with non-destructive imaging techniques, such as X-ray microtomography (XMT) (Bernard 2005; Luquot and Gouze 2009; Navarre-Sitchler et al. 2009; Noiriel et al. 2012; Luquot et al. 2014; Molins et al. 2014) and nuclear magnetic resonance (NMR) (Fridjonsson et al. 2011), provide powerful tools for studying pore-scale surface reactions, reaction-induced pore structure and permeability changes, and feedback between surface reactivity and reactive transport in porous media (Dupin and McCarty 2000; Nambi et al. 2003; Knutson et al. 2005; Willingham et al. 2008; Zhang et al. 2010b; Edery et al. 2013).

Numerical approaches are an important component of pore-scale geochemical research. Pore-scale flow and reactive transport models are used to simulate the temporal and spatial evolution of surface reactions in coupling with transport, to analyze and interpret experimental results, and to complement experimental approaches by extending experimental conditions. Commonly used numerical approaches include pore-network models (Acharya 2005; Li et al. 2006, 2007; Mehmani et al. 2012; Raoof et al. 2013; Varloteaux et al. 2013), lattice Boltzmann models (Kang et al. 2006, 2010, 2014; Knutson et al. 2007; Lichtner and Kang 2007; Zhang et al. 2008; Huber et al. 2014), smoothed particle hydrodynamics models (Tartakovsky et al. 2008b), and conventional finite-difference or finite-volume methods (van Duijn and Pop 2004, 2005; Willingham et al. 2008; Orgogozo et al. 2010; Porta et al. 2012, 2013; Yoon et al. 2012; Liu et al. 2013a; Steefel et al. 2013; Molins et al. 2014; Trebotich et al. 2014).

These models can explicitly incorporate pore geometry, reactive surface area, and distribution, and even molecular reaction rates to simulate coupled transport and reactions at the local scale and to provide insights into effective rates at the macroscopic scale.

Both experimental and numerical studies indicate that effective reaction rates can decrease by orders of magnitude from the molecular to macroscopic scale, with the magnitude decrease dependent on specific reactions and the structures of porous media (Swoboda-Colberg and Drever 1993; Malmström et al. 2000; Acharya et al. 2005; Li et al. 2006; Meile and Tuncay 2006; Navarre-Sitchler and Brantley 2007; Zhang et al. 2008; Bi et al. 2009; Flukiger and Bernard 2009; Zhang and Lv 2009; Miller et al. 2010; Liu et al. 2013a; Zhang et al. 2013b; Raoof et al. 2013; Salehikhoo et al. 2013). Various factors have been identified that may individually or collectively contribute to the scale-dependent behavior of geochemical reaction rates (Alekseyev et al. 1997; White and Brantley 2003; Meile and Tuncay 2006; Lichtner and Kang 2007; Steefel and Maher 2009; Maher 2010; Miller et al. 2010; Dentz et al. 2011; Liu et al. 2013a, 2014a). These factors can be grouped into two categories:

1) scale-dependent variations in mineral surface properties, such as surface roughness that controls reactive surface area and secondary mineralization that alters surface reactivity (White 1995; Alekseyev et al. 1997; Benner et al. 2002; White and Brantley 2003), and

2) heterogeneous distributions of flow, transport, and chemical properties in subsurface environments (Malmström et al. 2004; Li et al. 2006; Meile and Tuncay 2006; Lichtner and Kang 2007; Maher 2010; Shang et al. 2011; Liu et al. 2013a, 2014a; Zhang et al. 2013a).

Previous research into the existence and cause of scale-dependent reaction rates has targeted specific examples with relatively constrained physical and chemical conditions. 
General theories and/or approaches for systematically describing and conceptually predicting the scaling effect are under-developed. In this chapter, we begin with the development of a theoretical base for predicting the scale-dependent behavior of effective surface reaction rates in heterogeneous porous media, including explicit linkage of the effective reaction rate constant with its intrinsic rate constant and the important influence of pore-scale variations in reactant concentrations (see the Section Theoretical Consideration of Effective Reaction Rates). Approaches to estimate intrinsic reaction rates and rate constants are then discussed with emphasis on molecular simulations (see Intrinsic Rates and Rate Constants). We follow with examples of how the coupling of pore-scale subsurface reaction and transport processes creates variations in reactant concentrations, and how these, in turn, cause the effective rate constants to deviate from the intrinsic reaction rate constant as a function of time and space in: i) grain-scale reactive diffusion systems (see Grain-scale reactions, sub-grain process coupling, and effective rates) and ii) in reactive transport systems with fluid flow (see Subgrid variations in reactant concentrations and effective rate constants under flow conditions). We conclude with a summary of the results and discussion in this chapter, a concept to minimize the scale-dependent behavior of effective surface reaction rates in macroscopic models through consideration of subgrid heterogeneity, and a brief discussion of other potential important factors affecting reaction rate scaling.

\section{THEORETICAL CONSIDERATION OF EFFECTIVE REACTION RATES}

Geochemical reaction rates on mineral surfaces can be generally described using the mass action law:

$$
r_{i}=k_{\mathrm{ins}} A_{i} \prod_{j}\left(\gamma_{j} c_{j}\right)^{v_{i j}},
$$

where $r_{i}$ is the reaction rate, $k_{\text {ins }}$ is the intrinsic rate constant, $A_{i}$ is the reactive surface area, $c_{j}$ and $\gamma_{j}$ are the concentration and activity coefficient of chemical species $j, v_{i j}$ is the reaction order with respect to chemical species $j$. Rigorously, the mass action law (Eqn. 1) is only applicable at the pore scale, and concentrations and reaction rates in Equation (1) are defined locally at specific reactive surface locations or sites. As described in the following sections, the reactive surface locations and chemical species concentrations are generally heterogeneously distributed in subsurface materials. The observed and simulated chemical reaction rates in subsurface materials are effective reaction rates that are either explicitly or implicitly defined within a numerical grid cell volume that contains many pores and mineral surfaces. The grid cell volume can be the representative elemental volume (REV) to define Darcy-scale physical properties (Bear 1979), but most often it is a volume of porous media with its size constrained by computational resources and resolution need (Mo and Friedly 2000; Chiogna and Bellin 2013). Grid cells may be selected at different scales depending on applications (Fig. 1) including:

1) Earth system models (Harrison et al. 2009; Poudel et al. 2013) where an entire watershed may represent one numerical grid cell;

2) field scale numerical problems with numerical grid sizes ranging from meters to hundred meters (Scheibe et al. 2006; Maher 2010; Molins et al. 2010; Li et al. 2011; Bao et al. 2014);

3) core scale numerical simulations with numerical grid size from centimeter to meters (Zinn and Harvey 2003; Shang et al. 2011, 2014; Liu et al. 2014a); and

4) pore-scale research at the scales of $\mu \mathrm{m}$ to $\mathrm{mm}$ (Willingham et al. 2008; Zhang et al. 2013a). 


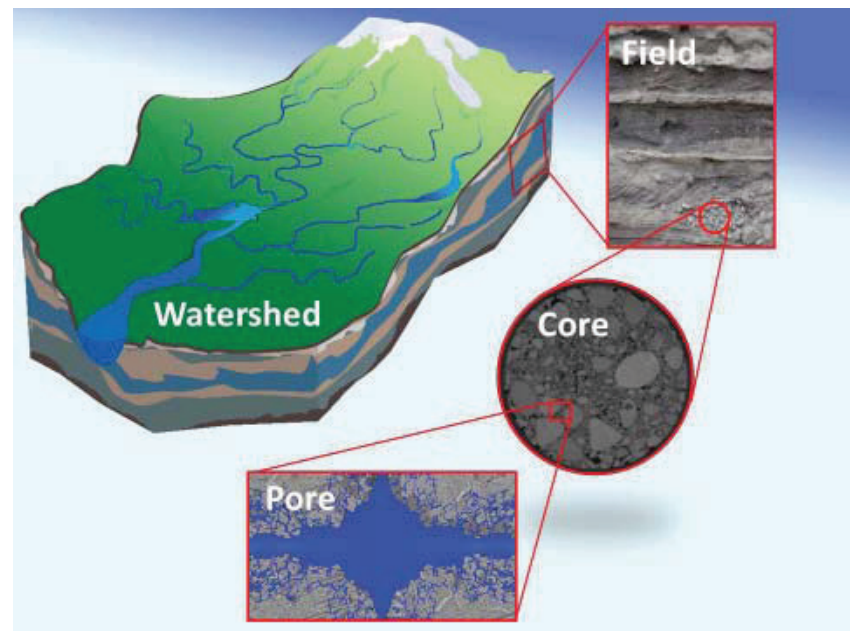

Figure 1. Schematic diagrams showing likely numerical grid scales for observations, experiments, and modeling.

Subgrid heterogeneity ranging from pore to large scales is a common feature of all these applications, indicating that Equation (1) is not directly applicable to describe effective reaction rates in heterogeneous subsurface materials.

To derive the effective reaction rate, Equation (1) is averaged over a porous medium volume $(\Delta V)$ to yield:

$$
\overline{r_{i}}=k_{\text {ins }} \overline{A_{i} \prod_{j}\left(\gamma_{j} c_{j}\right)^{v_{i j}}}
$$

where the variables with a bar are the average variables over the pore space within $\Delta V$. Using the average variables, pore-scale variables in Equation (1) can be written as the follows:

$$
\begin{aligned}
& A_{i}=\overline{A_{i}}+A_{i}{ }^{\prime}, \\
& c_{j}=\overline{c_{j}}+c_{j}{ }^{\prime}, \\
& \gamma_{j}=\overline{\gamma_{j}}+\gamma_{j}{ }^{\prime},
\end{aligned}
$$

where $A_{i}{ }^{\prime}, c_{j}{ }^{\prime}$, and $\gamma_{j}{ }^{\prime}$ are the deviations from their corresponding average values within $\Delta V$. Note that the average of $A_{i}{ }^{\prime}, c_{j}{ }^{\prime}$, or $\gamma_{j}{ }^{\prime}$ within $\Delta V$ is zero. Replacing Equations (3-5) into Equation (2) yields:

$$
\overline{r_{i}}=k_{\mathrm{ins}} \overline{A_{i}} \prod_{j}\left(\overline{\gamma_{j}} \overline{c_{j}}\right)^{v_{i j}} \overline{\left(1+\frac{A_{i}{ }^{\prime}}{\overline{A_{i}}}\right) \prod_{j}\left(\left(1+\frac{\gamma_{j}{ }^{\prime}}{\gamma_{j}}\right)\left(1+\frac{c_{j}{ }^{\prime}}{\overline{c_{j}}}\right)\right)^{v_{i j}}} .
$$

In subsurface systems, the relative deviation of the activity coefficient from its average value is typically small (Lasaga 1979). However, the relative deviations of pore-scale reactive 
surface area and chemical species concentrations from their average values within $\Delta V$ can be significant in heterogeneous materials. Equation (6) reveals that the effective reaction rate defined for $\Delta V$ is not only a function of average surface area and chemical species concentrations, but also depends on the pore-scale variations of these variables within $\Delta V$. The calculation of the pore-scale variations in Equation (6) requires detailed knowledge of pore structure, pore-scale chemical species concentrations, and reactive surface area or site concentration distributions. Such information is difficult to obtain in natural subsurface environments. Consequently, the pore-scale variations in Equation (6) are lumped into an effective rate constant:

$$
k_{\mathrm{eff}}=k_{\mathrm{ins}} \overline{\left(1+\frac{A_{i}^{\prime}}{\overline{A_{i}}}\right) \prod_{j}\left(\left(1+\frac{\gamma_{j}{ }^{\prime}}{\overline{\gamma_{j}}}\right)\left(1+\frac{c_{j}{ }^{\prime}}{\overline{c_{j}}}\right)\right)^{v_{i j}}},
$$

and the effective reaction rate in $\Delta V$ can be expressed using the average variables:

$$
\overline{r_{i}}=k_{\mathrm{eff}} \overline{A_{i}} \Pi_{j}\left(\overline{\gamma_{j}} \overline{c_{j}}\right)^{v_{i j}}
$$

Equation (8) has the same form as Equation (1). However, the variables and rate parameters are different. Equation (8) equals Equation (1) if the spatial variability of all variables is minimal in $\Delta V$, such as in a well-mixed system. Well-mixed systems are rare, and consequently Equation (8) is generally different from Equation (1). However, Equation (8) is used interchangeably with Equation (1) in most subsurface reactive transport studies and simulations. In these cases, an effective rate constant must be used instead of the intrinsic rate constant.

The effective rate constant is influenced by the relative deviations of pore-scale concentrations from their average values within $\Delta V$ (Eqn. 7). The relative deviation of reactive surface area depends on reactive mineral distribution and accessibility, as well as geochemical/ biogeochemical reactions that act on the surfaces and their potential to alter surface reactivity as reactions proceed. The concentrations of dissolved species will depend on not only surface reactions, but also transport processes that supply reactants at the pore scale and remove reaction products. Consequently, the effective rate constant $\left(k_{\text {eff }}\right)$ will be strongly affected by the coupling of reaction and transport, and will generally vary with space and time. Next we present several generic scenarios to demonstrate potential changes of $k_{\text {eff }}$ from its intrinsic value. In sections that follow, we discuss reactive transport studies to derive effective rate constants in heterogeneous porous media.

\section{Well-mixed conditions}

Under well-mixed conditions, the spatial variations in dissolved species concentrations are negligible. Although reactive surface area or reactive surface site concentration can be spatially variable, the effective reaction rate constant is the same as the intrinsic reaction rate constant:

$$
k_{\mathrm{eff}}=k_{\mathrm{ins}} \overline{\left(1+\frac{A_{i}^{\prime}}{\overline{A_{i}}}\right) \prod_{j}\left(\left(1+\frac{\gamma_{j}{ }^{\prime}}{\overline{\gamma_{j}}}\right)\left(1+\frac{c_{j}^{\prime}}{\overline{c_{j}}}\right)\right)^{v_{i j}}}=k_{\mathrm{ins}} \overline{\left(1+\frac{A_{i}{ }^{\prime}}{\overline{A_{i}}}\right)}=k_{\mathrm{ins}} .
$$

\section{Mass transport limited conditions}

For the convenience of demonstration, we first consider a case with only one dissolved species limiting the rate of a surface reaction (i.e., $j=1$ and $v_{i j}=1$ in Eqn. 1). Equation (7) can then be simplified after ignoring the pore-scale variation in activity coefficient: 


$$
k_{\mathrm{eff}}=k_{\mathrm{ins}}\left(1+\overline{\frac{A_{i}^{\prime}}{\overline{A_{i}}} \frac{c_{1}^{\prime}}{\overline{c_{1}}}}\right) .
$$

The pore-scale distribution of reactive area (or site concentration) is often negatively correlated with that of dissolved reactant concentrations under mass transport limited conditions in porous media. For example, finer-grained materials typically have a higher surface area and more reactive sites. These finer materials can form lenses, aggregates, coatings, or spots, which are less accessible to advective fluid due to the limitation of local hydraulic conductivity or pore connectivity. Consequently these regions may have lower concentrations of dissolved reactants supplied through fluid flow. Under this condition, Equation (10) predicts a lower $k_{\text {eff }}$ than $k_{\text {ins }}$, because the second term on the right hand site of Equation (10) is a negative value. With increasing size of $\Delta V$, large scale hydraulic heterogeneity, such as macroscopic flow channels, can affect the spatial distributions of reactants. This may further increase the range of dissolved reactant concentrations within $\Delta V$, and thus increase the negative magnitude of the second term on the right hand side of Equation (10). The net result is that the effective rate constant decreases with increasing scale (domain I in Fig. 2). Equation (10), however, also predicts an alternative scenario when the variations in reactive surface site and dissolved reactant concentration are positively correlated. When this happens, $k_{\text {eff }}$ will be larger than $k_{\text {ins }}$ (domain II in Fig. 2). This scenario requires that more reactive sites reside at locations where dissolved reactants are rapidly supplied.

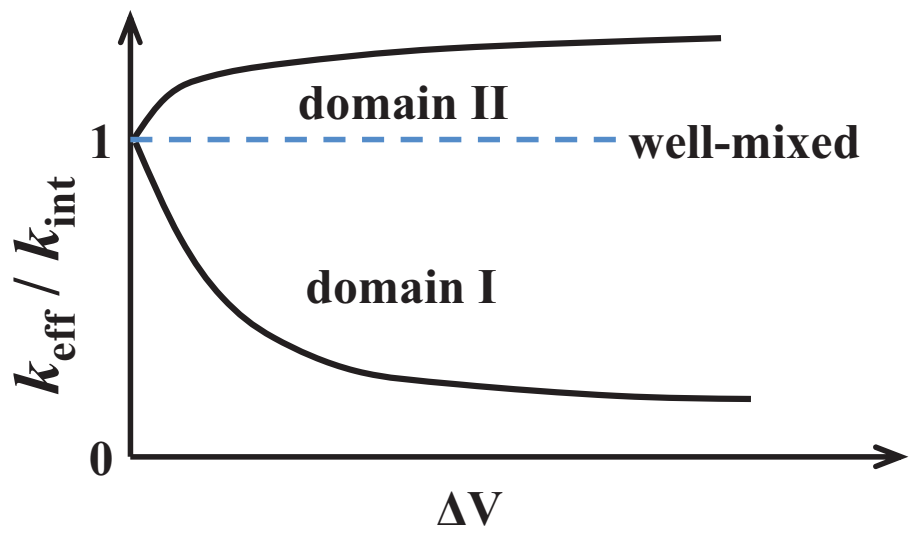

Figure 2. Effective rate constant as a function of numerical grid volume in heterogeneous porous media. Under well-mixed conditions, $k_{\text {eff }}=k_{\text {ins. }}$. Under mass transfer limited conditions, $k_{\text {eff }}$ can be smaller (domain I) or larger than $k_{\text {ins }}$ (domain II).

More complex scenarios can develop when two or more chemical reactants limit the rate of a surface reaction, or when a reaction is not first order with respect to a reactant. For example, when a second-order rate expression is considered with respect to dissolved species $j$ (i.e., $j=1, v_{i l}=2$ in Eqn. 1), then

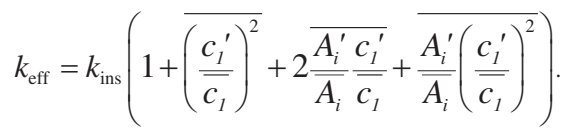


The bracketed value in Equation (11) not only depends on the pore-scale correlation between the variations in reactive surface site and dissolved reactant concentrations, but also on the relative strength of the self-correlation for variations in reactant concentration. A large, self-correlation in the variations of dissolved reactant concentration can decrease the effect of the negative correlation between dissolved species and reactive surface site concentrations, leading to less scale-dependent behavior. Similar complex scenarios can exist for reactions involving multiple reactants. For these cases, the effective rate constants in Figure 2 may not uniformly decrease or increase as scale increases.

\section{INTRINSIC RATES AND RATE CONSTANTS}

The effective rate constant is proportional to the intrinsic rate constant (Eqn. 7). Wellmixed experimental systems such as batch and stirred flow-cell reactors are often used to characterize reaction mechanisms and to estimate intrinsic rate constants that are independent of transport processes. Recently, molecular-scale simulations have been used to estimate kinetic rates and intrinsic rate constants. In this section, the most commonly used molecular simulation methods to calculate reaction rates are briefly described. The application of these methods for determining molecular-scale rates and rate constants of surface reactions are then discussed using several surface reaction examples.

\section{Approaches to calculate molecular-scale reaction rates}

Molecular dynamics (MD) is a powerful technique to study the molecular-scale behavior of geochemical systems (Stack et al. 2013). However, because the integration time step in MD simulations is constrained by the timescale for molecular vibrations that is usually on the order of 1 femtosecond, the simulated time that can be achieved routinely with MD simulations is limited to tens to hundreds of nanoseconds. Therefore, a range of techniques, referred to as rare-event techniques hereafter, have emerged with the goal of extending the timescale of MD simulations to investigate kinetic progress with rates that are lower than those manageable with standard MD algorithms. Examples of rare-event methods include transition path sampling (Dellago et al. 1998), metadynamics (Laio and Parrinello 2002), and reactive flux (Chandler 1987). A frequent application of the reactive flux approach to geochemically relevant systems is the study of water exchange reactions around aqueous ions (Rey and Guardia 1992; Rey and Hynes 1996a,b; Spångberg et al. 2003; Kerisit and Parker 2004b; Loeffler et al. 2006; Rustad and Stack 2006; Stack and Rustad 2007; Kerisit and Rosso 2009; Dang and Annapureddy 2013; Kerisit and Liu 2013). This same approach was subsequently applied to quantify the rates of surface complexation of aqueous ions on mineral surfaces (Kerisit and Parker 2004b) and eventually to look at attachment and detachment reactions at kink sites to simulate the elementary steps of mineral dissolution and growth (Stack et al. 2012).

In the reactive flux approach, the reaction rate is written as the product of the transition state rate constant, $k^{\mathrm{TST}}$, and the transmission coefficient, $\kappa$. The former corresponds to the rate at which the system reaches the transition state and is defined as

$$
k^{\mathrm{TST}}=\sqrt{\frac{\mathrm{k}_{\mathrm{B}} T}{2 \pi \mu}} \frac{\delta^{* 2} \exp \left[-\beta W\left(\delta^{*}\right)\right]}{\int_{0}^{\delta^{*}} \delta^{2} \exp [-\beta W(\delta)] \mathrm{d} \delta},
$$

where $\mu$ is the reduced mass of the atoms involved in the reaction, $\beta$ is $1 / \mathrm{k}_{\mathrm{B}} T$ where $\mathrm{k}_{\mathrm{B}}$ is the Boltzmann constant and $T$ is the temperature, $\delta$ is the reaction coordinate, $\delta^{*}$ is the value of the reaction coordinate at the transition state, and $W(\delta)$ is the free energy of the system at $\delta$, which can be obtained using a number of techniques, including the potential of mean force approach (PMF). In the PMF approach, separate MD simulations are performed with the 
system constrained at specific values of $\delta$, and the mean force along the reaction coordinate is integrated to obtain $W(\delta)$. The transmission coefficient accounts for the departure from ideal transition state behavior due to barrier re-crossing (i.e., not all trajectories that reach the transition state are successful transitions between the reactants and products free energy wells) and is determined from the plateau value of the normalized reactive flux, which can be computed as

$$
\kappa(t)=\frac{\langle\dot{\delta}(0) \theta[\delta(t)-\delta *]\rangle_{\mathrm{c}}}{\langle\dot{\delta}(0) \theta[\dot{\delta}(0)]\rangle_{\mathrm{c}}},
$$

where $\theta[x]$ is the Heaviside function, which is 1 if $x$ is larger than 0 and 0 otherwise, and $\delta(0)$ is the initial velocity along the reaction coordinate. The subscript ' $c$ ' denotes that the initial configurations are generated in the constrained reaction coordinate ensemble. The reactive flux is usually computed by running a large number of short trajectories forward and backward in time from initial configurations constrained at the transition state.

\section{Molecular-scale rates of uranyl sorption reactions at mineral surface sites}

Molecular simulation techniques have been used to study uranyl sorption at mineral surfaces (Kremleva et al. 2010; Geckeis et al. 2013). Mineral surfaces have included silica (Greathouse et al. 2002; Patsahan and Holovko 2007; Boily and Rosso 2011), alumina (Moskaleva et al. 2004; Glezakou and deJong 2011; Tan et al. 2013), iron and titanium oxides (Steele et al. 2002; Perron et al. 2006a,b, 2008 ; Drot et al. 2007; Sherman et al. 2008; Roques et al. 2009; Skomurski et al. 2011; Pan et al. 2012; Sebbari et al. 2012), phyllosilicates (Zaidan et al. 2003; Greathouse and Cygan 2005, 2006; Greathouse et al. 2005; Kremleva et al. 2008, 2011, 2012; Veilly et al. 2008; Hattori et al. 2009; Martorell et al. 2010; Lectez et al. 2012; Liu et al. 2013b; Yang and Zaoui 2013a,b; Teich-McGoldrick et al. 2014); feldspars (Kerisit and Liu 2012, 2014), and carbonates (Doudou et al. 2012). The majority of these studies focused on energy minimizations of adsorbed uranyl complexes at various mineral surfaces. As a whole, they have shown that significant variations exist in surface complex configurations and binding energies for different surfaces and sites of a given mineral. Although adsorption rates were not calculated in most cases, this body of work strongly suggests that molecularscale heterogeneities should influence the adsorption/desorption rates of uranyl for a given mineral. For example, static density functional theory (DFT) calculations of uranyl surface complexation on the basal and edge surfaces of kaolinite $\left(\mathrm{Al}_{2} \mathrm{Si}_{2} \mathrm{O}_{5}(\mathrm{OH})_{4}\right)$ (Kremleva et al. 2008, 2011; Martorell et al. 2010) revealed significant differences between the tetrahedral Si layer and the octahedral Al layer, as well as a wide range of binding energies on different sites om the (010) edge surface. Similar conclusions were drawn from simulations of uranyl surface complexation on pyrophyllite $\left(\mathrm{Al}_{2} \mathrm{Si}_{4} \mathrm{O}_{10}(\mathrm{OH})_{2}\right)$ edge surfaces (Kremleva et al. 2012), where it was concluded that multiple adsorbed complexes likely exist on any given surface, and that different edge surfaces exhibit different preferred surface complex coordination environments.

A small subset of these studies investigated the kinetics of uranyl sorption. For example, MD simulations by Boily and Rosso (2011) using PMF calculations showed significantly different barrier heights for uranyl adsorption/desorption on three quartz $\left(\alpha-\mathrm{SiO}_{2}\right)$ surfaces, providing further evidence that sorption rates are heterogeneous at the molecular scale even for a given mineral. MD simulations of uranyl sorption on the most stable surfaces of orthoclase $\left(\mathrm{KAlSi}_{3} \mathrm{O}_{8}\right.$ - tectosilicate) and kaolinite (phyllosilicate) (Kerisit and Liu 2012, 2014) revealed large quantitative differences in the free energy barriers for adsorption/desorption as well as in the affinity of uranyl for these two types of silicate minerals. The formation of uranyl carbonate complexes affected desorption free energy barriers on the two minerals to different extents, indicating that variations among mineral phases can be compounded by solution 
conditions that impact aqueous speciation. Desorption rates of adsorbed uranyl orthoclase were calculated to be on the order of $10^{6} \mathrm{hr}^{-1}$ (Kerisit and Liu 2012), a rate several orders of magnitude faster than the grain-scale rate constant (Liu et al. 2013a).

\section{Molecular-scale rates of elementary mechanisms of mineral growth and dissolution}

Initial applications of rare-event techniques such as reactive flux to calculate molecularscale rates of mechanisms relevant to mineral growth and dissolution focused on adsorption of ions on ideal, planar surfaces (i.e., formation of adatoms) (Piana et al. 2006; Kerisit and Parker $2004 a, b)$. For example, adsorption of alkaline-earth cations on the $\{10 \overline{1} 4\}$ calcite surface was found to be very fast $\left(\sim 10^{8} \mathrm{~s}^{-1}\right)$ and desorption was calculated to be only marginally slower $\left(\sim 10^{6}-10^{7} \mathrm{~s}^{1}\right)$ (Kerisit and Parker 2004b), demonstrating the presence of labile species on flat surfaces. The exact values of these rates as well as the extent of the driving force for adsorption is dependent on the details of the force-field parameters (Raiteri and Gale 2010). Similar free-energy barriers for adsorption/desorption were obtained by Piana et al. (2006) for $\mathrm{Ba}^{2+}$ on a pure, flat $\{001\}$ barite $\left(\mathrm{BaSO}_{4}\right)$ surface. In contrast, detachment rates of $\mathrm{Ba}^{2+}$ from a step edge on the same surface were determined by Stack et al. (2012) to be much slower $\left(\sim 10^{4} \mathrm{~s}^{-1}\right)$. Therefore, orders of magnitude differences in adsorption and desorption rates can exist between different sites and surface structures on the same mineral surface.

The work of Piana et al. (2006) on $\mathrm{Ba}^{2+}$ sorption on three barite surfaces also demonstrated that the free-energy barrier for adsorption is strongly surface specific and can be significantly reduced by the presence of anions adsorbed on the surface, indicating that the sequence of sorption events plays an important role in determining the overall reaction rate. MD simulations of $\mathrm{Ca}^{2+}$ and $\mathrm{CO}_{3}{ }^{2-}$ dissolution from calcite surfaces also resulted in free-energy barriers that were heavily surface specific (Spagnoli et al. 2006). In addition, detailed rare-event simulations of $\mathrm{Ba}^{2+}$ attachment and detachment to/from a stepped surface by Stack et al. (2012) highlighted that, even for this seemingly simple surface reaction, multiple intermediates were involved with a wide range of transition rates between intermediates $\left(10^{4}\right.$ to $\left.10^{10} \mathrm{~s}^{-1}\right)$. Rareevent techniques have also improved understanding of mineral nucleation. For example, MD simulations demonstrated importance of precursor amorphous clusters in $\mathrm{CaCO}_{3}$ homogenous nucleation by demonstrating the presence of small free energy barriers and favorable reaction free energies for the addition of $\mathrm{CaCO}_{3}$ ion pairs to a growing nucleus (Tribello et al. 2009; Raiteri et al. 2010).

The studies described above made use of classical MD techniques due to the large size of the simulated systems. Another approach to computationally probe the rates of mineral growth and dissolution involves the use of small clusters that are treated quantum mechanically to represent surface sites and that can be immersed in a continuum dielectric model to simulate solvation effects. With this approach, potential energy surfaces can be obtained by progressively elongating bonds within the clusters to evaluate the energetics of mineral dissolution. Although the effects of the extended crystal structure are lost with this approach, it allows for the making/breaking of covalent bonds and investigating the effects of $\mathrm{pH}$. In particular, this approach has been applied, for example, to study the dissolution of silicate minerals such as olivine (Morrow et al. 2010) and feldspar (Criscenti et al. 2005, 2006).

\section{GRAIN-SCALE REACTIONS, SUB-GRAIN PROCESS COUPLING, AND EFFECTIVE RATES}

Subsurface materials contain microscopic pores and/or fractures within individual minerals, grains, and grain-aggregates (Anbeek 1993; Berkowitz and Scher 1998; Lee et al. 1998; White et al. 2001; Berkowitz 2002; Zachara et al. 2004; Liu et al. 2006; Luquot and Gouze 2009; Hay et al. 2011). These intra-granular porous domains have pore sizes ranging 
from nanometers to tens of micrometers, and have a high interfacial surface area to pore volume ratio (Anbeek 1993; Hurlimann et al. 1994). Various geochemical reactions can occur in the intra-granular pore domains that affect bulk solution chemistry in external pore regions (Barber Ii et al. 1992; McGreavy et al. 1992; Anbeek 1993; Lee et al. 1998; Liu et al. 2006; McKinley et al. 2006, 2007). The transport in these intra-granular domains is dominated by diffusion that is strongly affected by pore connectivity (Ewing et al. 2012). Slow diffusion process allows intra-granular solutions to evolve close to mineral equilibrium that can deviate from that in bulk solutions. Geochemical reactions such as sorption/desorption (Ball and Roberts 1991; Qafoku et al. 2005; Liu et al. 2008; Ginn 2009) and mineral precipitation and dissolution (McGreavy et al. 1992; Lee et al. 1998; Anderson et al. 2002; Liu et al. 2006; McKinley et al. 2006, 2007; Pallud et al. 2010a) can occur in defiance of thermodynamic conditions in bulk solutions. The slow diffusion, on the other hand, decreases mass exchange rate with external pore waters, leading to non-ideal behavior of chemical transport even for non-reactive species (Beven and Germann 1982; Ball and Roberts 1991; Ewing et al. 2010, 2012; Hay et al. 2011).

Micromodel experimental systems have been used to evaluate the relationship between the intrinsic and effective rate constants (Zhang et al. 2013a; Liu et al. 2015). Micromodels can be fabricated to simulate the complex physical structure of natural sediment grains and grainaggregates. Figure 3 shows an example of micromodel systems. The four corner regions in the micromodel (Fig. 3) are composed of grain aggregates and intra-aggregate pores. Surrounded by the aggregates is a macropore domain where advection dominates. The micromodel system has been used to provide insights into the scale-dependent variation in the effective rate of uranyl desorption that is over 3-5 orders of magnitude slower than the intrinsic rate estimated from molecular simulations (Liu et al. 2013a). It has also been used to examine hematite reduction in heterogeneous media under flow conditions and to investigate the difference in effective rate constants between well-mixed and heterogeneous transport systems (Zhang et al. 2013a).

These examples display the importance of the coupling of transport and reaction at the pore-scale in controlling the grain-scale reaction rates. Accurate simulations of grain-scale reaction rates are, however, challenged by the difficulties in the estimation of effective reaction rates in both intra- and inter-granular domains (Liu et al. 2006; Zhang et al. 2013a). We now demonstrate how a pore-scale reactive diffusion model can be used to simulate the variability in reactant concentrations in intra-granular domains. The simulated concentrations are then

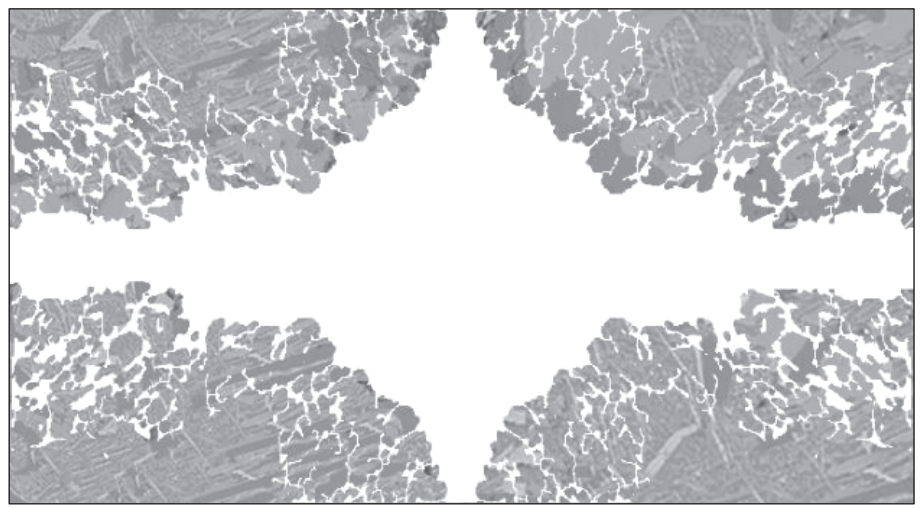

Figure 3. A micromodel system abstracted from imaging analysis of grain aggregates (4 corner regions) (from Zhang et al. 2013a). 
used by Equation (7) to calculate effective rate constants for grain-scale reactive transport models. Grain-scale models based on mass transfer and diffusion will be compared to assess how different physical models influence the deviation between effective and intrinsic rate constants.

\section{Pore-scale variability in reactant concentrations at the sub-grain scale}

The evolution of reactant concentrations in intra-granular domains can be described using a reactive diffusion equation:

$$
\frac{\partial c_{j}}{\partial t}=\nabla \cdot\left(D_{j} \nabla c_{j}\right)+\sum_{i=1}^{N_{r}} a_{j i} r_{i}, \quad j=1,2, \ldots N,
$$

where $D_{i}$ is the molecular diffusion coefficient of aqueous chemical species $j, a_{j i}$ is the stoichiometric coefficient of species $j$ in reaction $i, N_{r}$ and $N$ are the total numbers of kinetic reactions and species in the system, respectively, and the other variables are defined before for Equation (1). Various numerical approaches exist for solving the multi-species diffusion problem described by Equation (14) using implicit or explicit numerical scheme, or their combination (Yeh and Tripathi 1991; Press et al. 1992; Liu et al. 2011).

The reactive diffusion equation (Eqn. 14) was used to simulate pore-scale variations in reactive surface site and dissolved species concentrations during hematite reduction in the intra-granular pore spaces as shown in the four corner regions in the micromodel (Fig. 3). In this example, hematite is assumed to be uniformly distributed on all the pore surfaces (bottom and side walls) in both intra- and inter-granular domains in the micromodel. The experimental design, micromodel fabrication, and hematite deposition on the pore surfaces for this example have been detailed elsewhere (Zhang et al. 2013a). To initiate hematite reduction in the intragranular domain for the modeling purpose, reduced flavin mononucleotide $\left(\mathrm{FMNH}_{2}\right)$ with a constant concentration $(100 \mu \mathrm{M})$ was provided in the external pore space (center white region in Fig. 3). $\mathrm{FMNH}_{2}$ is a biogenic organic molecule capable of reducing iron oxides (Marsili et al. 2008; Shi et al. 2012). Driven by the concentration gradient, $\mathrm{FMNH}_{2}$ diffuses into the intragranular domains where it reacts with hematite on pore surfaces. Hematite $\left(\mathrm{Fe}_{2} \mathrm{O}_{3}\right)$ undergoes reductive dissolution to yield $\mathrm{Fe}(\mathrm{II})$ and $\mathrm{FMN}$, which is an oxidized form of $\mathrm{FMNH}_{2}$. The kinetics of hematite reduction in a well-mixed system follows the rate expression (Liu et al. 2007; Shi et al. 2012; Zhang et al. 2013a):

$$
r=k_{\mathrm{ins}} c_{\mathrm{Fe}_{2} \mathrm{O}_{3}} c_{\mathrm{FMNH}_{2}},
$$

where $c_{\mathrm{Fe}_{2} \mathrm{O}_{3}}$ is the pore-scale hematite concentration on the mineral surfaces $(\mu \mathrm{M}), c_{\mathrm{FMNH}_{2}}$ is the pore-scale aqueous concentration $(\mu \mathrm{M})$, and $k_{\text {ins }}$ is the rate constant at the pore-scale $\left(\mu \mathrm{M}^{-1} \mathrm{~h}^{-1}\right)$, which is equivalent to the intrinsic rate constant for this study (Eqn. 7). Equation (14) and Equation (15) were solved using the finite-volume method with a constant numerical node size of $10 \times 10 \mu \mathrm{m}^{2}$. The initial hematite concentration on each pore surface is $0.73 \mu \mathrm{mol} / \mathrm{cm}^{2}$ in the micromodel. The surface based hematite concentration was converted to volumetric concentration using a surface area of $10 \times 28 \mu \mathrm{m}^{2}$ for the side wall and $10 \times 10 \mu \mathrm{m}^{2}$ for the bottom surface wall.

The statistical distributions of $\mathrm{FMNH}_{2}$ and residual hematite concentrations in the intraaggregate domains were calculated to vary with time (Fig. 4). Initially, $\mathrm{FMNH}_{2}$ concentrations were zero at all diffusion nodes (Fig. 4A). Initial hematite concentration was one of five possible values after normalizing to local pore node volume ( 5 red bars in Fig. 4B), a consequence of the fact that each pore node can contain 1 bottom pore wall, and additional zero to four side walls of hematite depending on the topology of water-grain interfaces in a grid node. The corresponding five possible hematite concentrations were $0.26,0.99,1.72,2.45$, 

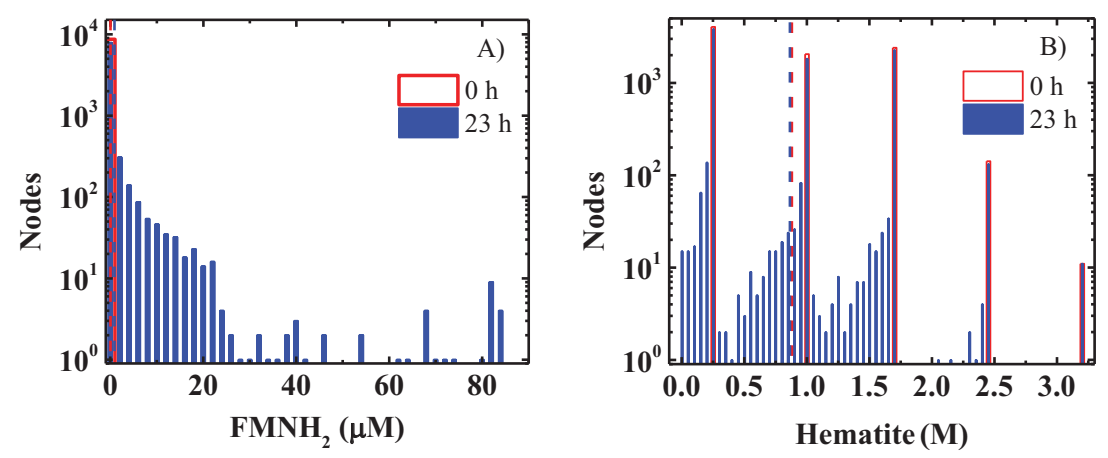

Figure 4. A) Pore-scale $\mathrm{FMNH}_{2}$ concentrations in the intra-granular domain, and B) residual hematite concentrations in the intra-granular domain. Dash lines are the average concentrations. A red line denotes the results at time zero, and the blue line denotes the results after 23 hours of coupled $\mathrm{FMNH}_{2}$ diffusion and hematite reduction.

and $3.18 \mathrm{M}$. The high molar concentration of hematite resulted from a high surface to pore volume ratio at the pore-scale. After 23 hours of $\mathrm{FMNH}_{2}$ diffusion and hematite reduction, the $\mathrm{FMNH}_{2}$ concentration distribution shifted toward higher concentrations (Fig. 4A), while the hematite concentration distribution shifted toward lower concentration (Fig. 4B). The hematite concentrations in nodes with four side pore walls did not change, because those nodes were not connected to external pore regions. Nodes with the larger decrease in hematite concentrations were those containing higher concentrations of $\mathrm{FMNH}_{2}$, which lead, in turn, to the negative correlation between hematite and $\mathrm{FMNH}_{2}$ concentrations at later times. This correlation affected the effective rate constant in the intra-granular domain as discussed in the next subsection.

\section{Effective reaction rates and rate constants}

The intra-granular diffusion domain is often termed as the immobile domain and external pore regions where water flows is often termed as the mobile domain in hydrology. The mass transfer between mobile and immobile domains is often described using the first-order mass exchange equation (Brusseau et al. 1992; Haggerty and Gorelick 1995; Šimunek et al. 2003):

$$
\frac{\partial c_{j}^{\mathrm{im}}}{\partial t}=k_{\mathrm{m}}\left(c_{j}^{\mathrm{m}}-c_{j}^{\mathrm{im}}\right),
$$

where $c_{j}^{\mathrm{im}}$ is the average concentration of species $j$ in the immobile domain, $c_{j}^{\mathrm{m}}$ is the average concentration in the mobile domain, and $k_{\mathrm{m}}$ is the mass transfer coefficient. In this model, the spatial change in species concentrations in the immobile domain is no longer considered. Using this model to include reactions in the immobile domain, Equation (16) becomes:

$$
\frac{\partial c_{j}^{\mathrm{im}}}{\partial t}=k_{\mathrm{m}}\left(c_{j}^{\mathrm{m}}-c_{j}^{\mathrm{im}}\right)+\sum_{i=1}^{N r} a_{j i} r_{i}^{\mathrm{im}},
$$

where $r_{i}^{\mathrm{im}}$ is the average rate of reaction $i$ in the immobile domain. Using terminology for Equation (7), the reaction rate in Equation (17) can be expressed as the follows for the case of hematite reduction in the micromodel (Fig. 4),

$$
r_{i}^{\mathrm{im}}=\overline{r_{i}}=k_{\mathrm{eff}} \overline{c_{\mathrm{Fe}_{2} \mathrm{O}_{3}}} \overline{c_{\mathrm{FMNH}_{2}}} .
$$


From Equation (7), we have

$$
\frac{k_{\text {eff }}}{k_{\text {ins }}}=1+\frac{\overline{\left(c_{\mathrm{Fe}_{2} \mathrm{O}_{3}}-\overline{c_{\mathrm{Fe}_{2} \mathrm{O}_{3}}}\right)}\left(\overline{\left.c_{\mathrm{FMNH}_{2}}-\overline{c_{\mathrm{FMNH}_{2}}}\right)}\right.}{\overline{c_{\mathrm{Fe}_{2} \mathrm{O}_{3}}} \overline{c_{\mathrm{FMNH}_{2}}}} .
$$

The ratio of the effective rate constant to intrinsic rate constant can be calculated using the pore-scale concentration results in Figure 4. The calculated effective rate constant (Fig. 5) was lower than the intrinsic rate constant and decreased with increasing time. This was because residual hematite concentration was increasingly negatively correlated with the $\mathrm{FMNH}_{2}$ concentration distribution in the diffusion domain as hematite reductively dissolved. Note that the simulation was only run for 23 hours in this case, and the effective rate constant is expected to further decrease with time, before it eventually increases back to 1 when all hematite is reduced and dissolves.

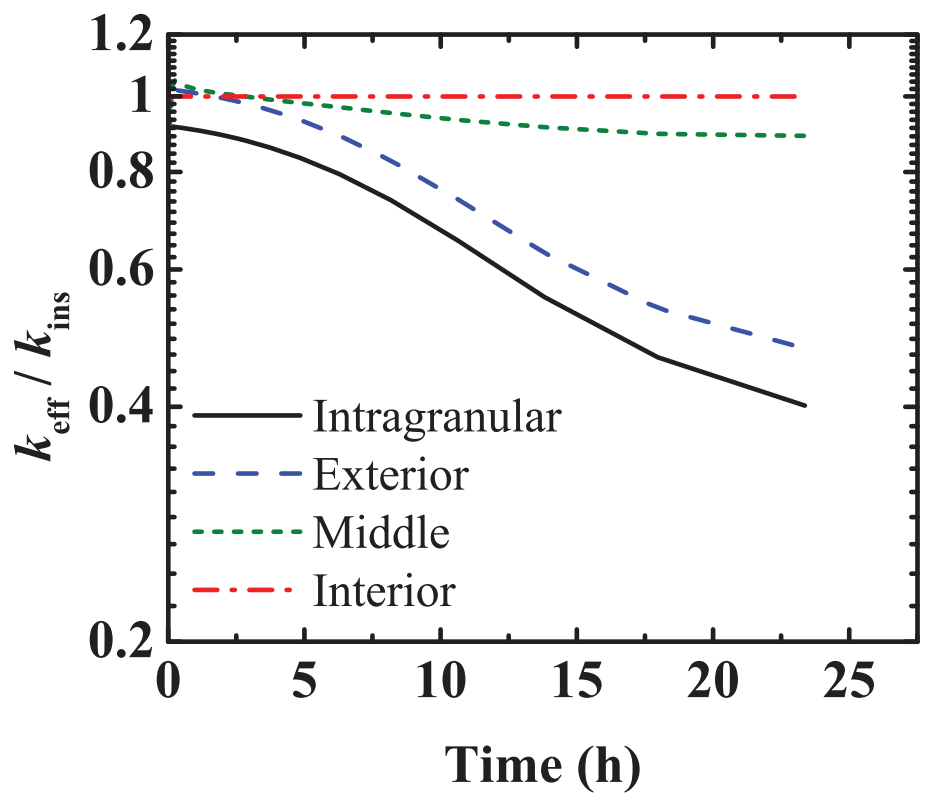

Figure 5. Deviation of effective hematite-reduction rate constant from the intrinsic value in the intragranular domain. Solid line showing the effective rate constant for the entire intra-granular domain; dashed lines are the effective rate constants for three numerical nodes within the intra-granular domain.

Diffusion models, such as one-dimensional slab or spherical diffusion models (Crank 1975; Ball and Roberts 1991) represent an alternative approach to describe intra-granular reactions and mass exchange with the mobile domain:

$$
\frac{\partial c_{j}^{\mathrm{im}}}{\partial t}=\nabla \cdot\left(D_{a} \nabla c_{j}^{\mathrm{im}}\right)+\sum_{i=1}^{N r} a_{j i} i_{i}^{\mathrm{im}},
$$

where $D_{a}$ is the effective diffusivity. The diffusion model is macroscopic without considering details in pore structure and connectivity in the intra-granular domain. However, Figure 6 
shows that the effective reaction rate constants become closer to the intrinsic rate constant using the diffusion model. In this specific case, a slab reactive diffusion model was used, and the intra-granular macroscopic diffusion domain was divided into 3 numerical nodes (exterior, which is close to external pore space; interior, which is the farthest from external pore space; and middle, which is between exterior and interior nodes). The effective reaction rate constant in each node was calculated using the simulated pore-scale concentrations of $\mathrm{FMNH}_{2}$ and residual hematite within a specific numerical node. The calculated effective reaction rate constants still deviate from the intrinsic value in each numerical node with a largest deviation observed in the exterior node (Fig. 5). The deviation correlates with the concentration change that was the greatest in the exterior node. It is expected that the effective rate constant in each node will become closer to the intrinsic rate constant when more numerical nodes are used. However, complete elimination of the deviation between the effective and intrinsic rate constants cannot be achieved regardless of the number of numerical nodes used in discretizing Equation 20, because of the macroscopic nature of the grain-scale diffusion model.

The effective rate constant also changed with numerical grid size when a macroscopic model is used to describe the reaction in the intra-granular domain (Fig. 6). Figure 6 only shows the results for two types of grain-scale grid node sizes:

1) the intra-granular domain was divided into 3 numerical nodes (grid node size $=700 \mathrm{~mm}$, subgrain scale), and

2) the intra-granular domain was treated as one numerical grid node (grid node size $=2000 \mathrm{~mm}$, grain scale) in corresponding to the results in Figure 5.

The effective rate constant generally decreased with increasing grid size (Fig. 6); however, its value varied significantly at each grid size scale, reflecting spatial and temporal changes in pore-scale concentrations of reactants and their correlation (Fig. 4). The effective rate constants in Figure 6 were calculated using the pore-scale concentrations at time 5, 15, and 23 hours of $\mathrm{FMNH}_{2}$ diffusion and hematite reduction. It is expected to have a wider range of effective rate constant distribution when other time results are also included.

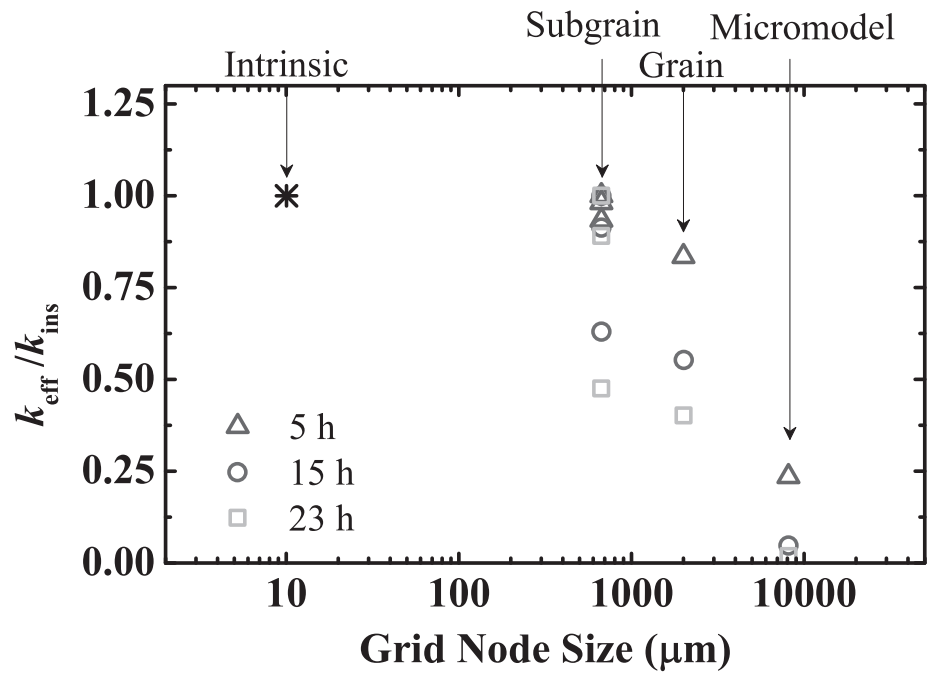

Figure 6. Effective hematite-reduction rate constant as a function of numerical grid node size at three different observation times $(5,15$, and $23 \mathrm{~h})$ after hematite reduction. 


\section{SUBGRID VARIATIONS IN REACTANT CONCENTRATIONS AND EFFECTIVE RATE CONSTANTS UNDER FLOW CONDITIONS}

Subsurface materials are heterogeneous in many ways (Fig. 1) in addition to intragranular complexity in pore structure and reactivity (Figs. 3 and 4). A numerical grid system used for simulating large scale reactive transport typically contains heterogeneity in both intraand inter-granular domains within individual grid nodes. This heterogeneity is referred to as subgrid heterogeneity, which has been attributed to 5-7 orders of magnitude decrease in the effective rate of $\mathrm{U}(\mathrm{VI})$ desorption in sediments from the molecular to field scales (Liu et al. 2013a, 2014a; Ma et al. 2014), and four orders of magnitude decrease for microbial reduction of uranium from laboratory to field systems (Bao et al. 2014). Here the micromodel system (Fig. 3) was used again to demonstrate how to:

1) calculate the variations in reactant concentrations in systems with subgrid heterogeneity, and

2) use the calculated results to estimate effective rate constant as a function of space and time.

Macroscopic reactive transport models with and without considering subgrid heterogeneity are compared to evaluate their effect on the estimated effective rate constants.

\section{Pore-scale concentration variations under flow conditions}

Simulations of pore-scale reactive transport under flow conditions require calculating fluid flow and chemical reactive transport. Fluid flow at the pore-scale can be generally described using the Navier-Stokes (N-S) equation (Bird et al. 2007).

$$
\frac{\partial \mathbf{u}}{\partial t}+\mathbf{u} \cdot \nabla \mathbf{u}=-g \nabla h+v \nabla^{2} \mathbf{u}+\mathbf{g},
$$

where $\mathbf{u}$ is the velocity vector, $g$ is the gravitational constant, $\mathbf{g}$ is the gravitational force, $h$ is the pressure or water head, and $\nu$ is the effective kinematic viscosity $(\nu=\mu / \rho$, where $\mu$ is the dynamic viscosity and $\rho$ is the fluid density). The simulation of fluid flow using Equation (21) requires knowledge of the pore geometry. However, soil and sediment systems are heterogeneous, consisting of various sizes of pores, minerals, organic matter, and organisms, often exhibiting hierarchical structures spanning seven or more order of magnitude. Pore size distribution can be quantified to the nm scale by direct and indirect methods including mercury porosimetry and neutron scattering, but the important pore network is much more difficult to define, especially at scale of $<1 \mu \mathrm{m}$ (Ball et al. 1990; Hay et al. 2011). This creates a scenario that pore geometry for large pores can be spatially resolved, while that for small pores is below spatial resolution. The soil and sediment domains containing small pores will therefore have to be treated as porous media (mixed pores and solids with unknown pore geometry) in numerical discretization. This will prevent the direct application of Equation (21) to describe fluid flow in soils and sediments. An alternative model has recently been developed to describe fluid flow in mixed media containing both pores and porous domains (Yang et al. 2014). The model becomes N-S in the pore regions, and becomes a Darcy-law-based model for fluid flow in the porous domain.

When the fluid velocity field is specified, the reactive solute transport can be simulated using the pore-scale multi-species advection and diffusion equations coupled with reactions:

$$
\frac{\partial c_{j}}{\partial t}=\nabla \cdot\left(D_{j} \nabla c_{j}\right)-\mathbf{u} \cdot \nabla c_{j}+\sum_{i=1}^{N_{r}} a_{j i} r_{i}, j=1,2, \cdots N .
$$


Equations (21) and (22) were used to simulate fluid flow, hematite reduction, and reactive transport in the micromodel (Fig. 3) to calculate reactant variations with time. $\mathrm{FMNH}_{2}(100 \mu \mathrm{M})$ was injected from the left side of the micromodel with a constant flow rate $(270 \mu \mathrm{L} / \mathrm{h})$. The injected $\mathrm{FMNH}_{2}$ reacts with hematite on pore surfaces in both inter- and intra-granular domains. Hematite was reduced and dissolved quickly in the advection domain (red region) as $\mathrm{FMNH}_{2}$ carried by fluid from the left side reacted with the hematite on the bottom pore wall in the advection domain (Fig. 7). There were regions near the grain-grain contacts in the inter-granular pore domain (center up and bottom, Fig. 7), where hematite reduction was much slower than that in the advection domain. These regions mimic the wedge spaces or dead end pores created by grain-grain contacts in porous media. This slow reduction region is termed as the macropore diffusion domain, as the advection bypasses these regions (Zhang et al. 2013a; Liu et al. 2015).

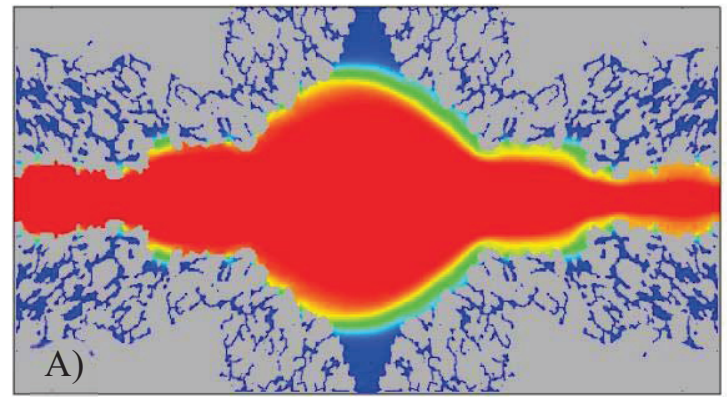

\section{FMNH2 (uM)}
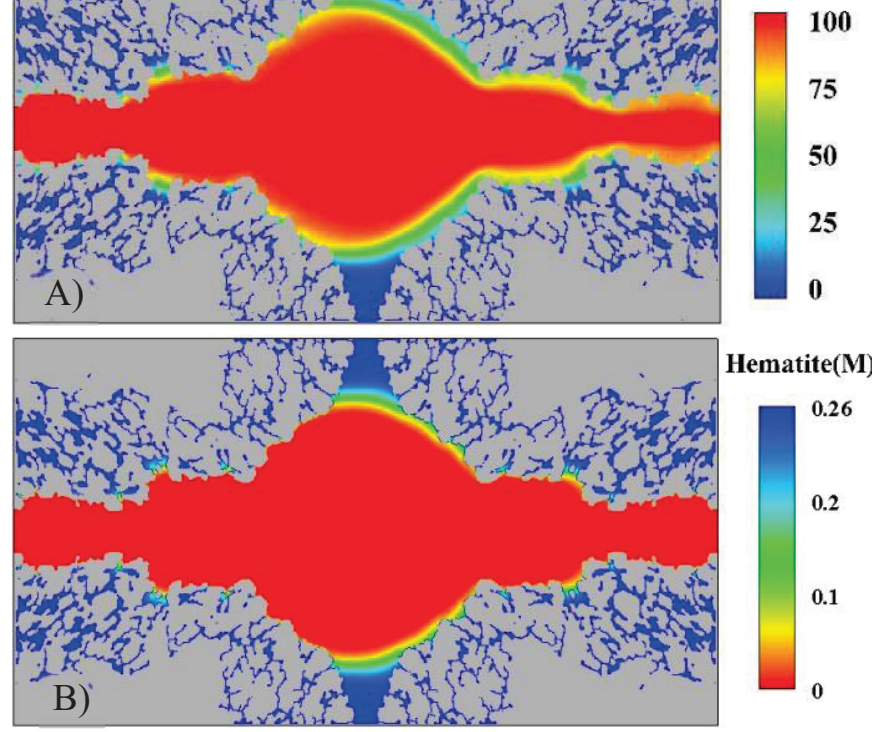

Figure 7. Snapshots of pore-scale distributions of $\mathrm{FMNH}_{2}$ (plot A) and residual hematite (plot B) concentrations in the micromodel after 23 hours of $\mathrm{FMNH}_{2}$ injection and hematite reduction (From Liu et al. 2015).

The hematite-reduction front migrated from the advection domain to the macropore and intra-granular diffusion domains through $\mathrm{FMNH}_{2}$ diffusion. Figure 7 only shows one snapshot. The hematite-reduction fronts moved further into the diffusion domains with continual $\mathrm{FMNH}_{2}$ injection. Eventually all hematite in the macropore diffusion domain was reduced. The reduction rate in the intra-granular domain was, however, much slower as discussed previously. Note that the initial $\mathrm{FMNH}_{2}$ concentration was zero and initial hematite concentration was one of 5 possible values depending on topology of water-grain interfaces in the grid node. After 23 hours of reduction, the $\mathrm{FMNH}_{2}$ concentration in most pores in the advection domain was equal to the $\mathrm{FMNH}_{2}$ concentration in the injection solution $(=100 \mu \mathrm{M})$; but its concentration was still zero in the interior of the intra-granular domain. The net result is a wide distribution of $\mathrm{FMNH}_{2}$ concentration (Fig. 8). The average concentration of $\mathrm{FMNH}_{2}$ 
increased in the micromodel, while the residual hematite concentration decreased with time (dashed lines in Fig. 8). Those nodes with a higher $\mathrm{FMNH}_{2}$ concentration have a lower concentration of hematite than their average concentrations, leading to a negative value for the second right-hand term in Equation (7).
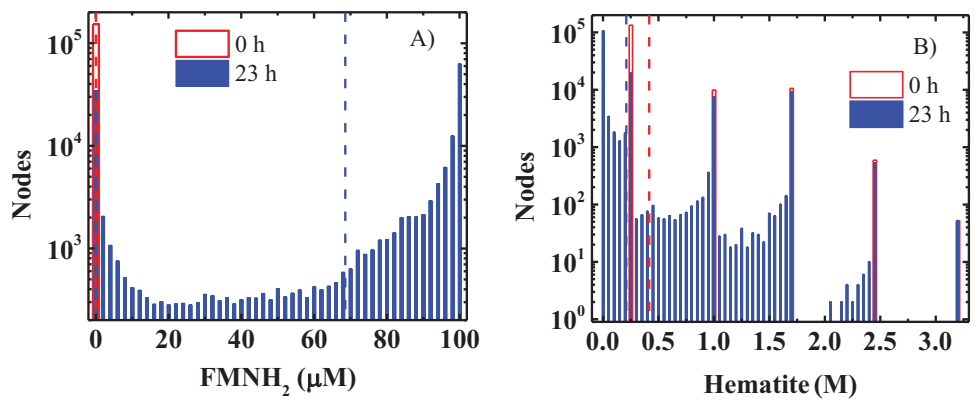

Figure 8. Statistics of pore-scale concentrations of $\mathrm{FMNH}_{2}$ (plot A) and residual hematite (plot B) in the micromodel at time zero and after 23 hours of $\mathrm{FMNH}_{2}$ injection and reaction. Dash lines are the average concentrations. The red line denotes the results at time zero, and the blue line denotes results at time 23 hours.

\section{Effective rate constants}

The effective overall rate constant for the micromodel (calculated using the results in Fig. 8 and Eqn. 7) decreased by two orders of magnitude during the first 23 hours of the hematite-FMNH $\mathrm{F}_{2}$ reaction (Fig. 9A). Ratio of $k_{\text {eff }} / k_{\text {ins }}$ decreased immediately from 1 to about 0.75 within a few seconds of $\mathrm{FMNH}_{2}$ injection because of a fast hematite reduction in the advection domain. After that, the effective rate decreased steadily with time. The effective rate
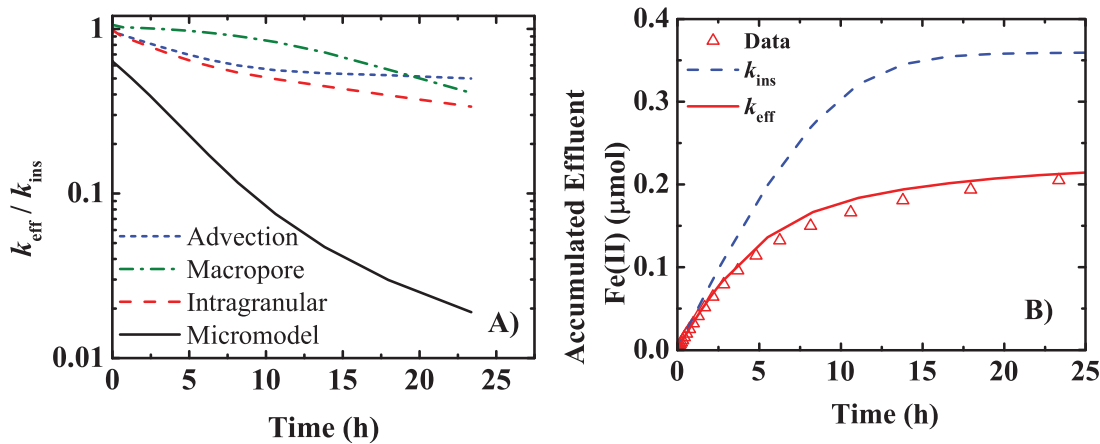

Figure 9. A): Deviation of effective hematite-reduction rate constant from the intrinsic rate constant as a function of time for the entire micromodel (solid line), and for subgrid domains: advection domain (short dashed line), macropore diffusion domain (dash-dot line), and intra-granular domain (dashed line). B) predicted Fe(II) mass accumulated in effluent as a result of hematite reduction in the micromodel. The solid line is the result simulated using the calculated effective rate constant for the micromodel, and the dashed line is the result simulated using the intrinsic rate constant. Triangles are the measured effluent Fe(II) (red triangles) (Liu et al. 2015). 
constant for the micromodel was lower than the effective rate for the intra-granular domain (Fig. 6), as a result of larger concentration variations in the micromodel than those in the intragranular domain only. The effluent concentration of $\mathrm{Fe}(\mathrm{II})$ produced from hematite reduction can be predicted using the effective rate for the micromodel under the assumption that the micromodel was a well-mixed system (Fig. 9B). By comparison, the model significantly overpredicted effluent $\mathrm{Fe}(\mathrm{II})$ if an intrinsic rate constant was used in the well-mixed model.

The above analysis of the effective rate constant treats the entire micromodel as a wellmixed reactor, or as one numerical grid volume in a reactive transport systems. The estimated effective rate constant reflects the pore-scale deviations in $\mathrm{FMNH}_{2}$ and hematite concentrations from their average values in the micromodel pore network (Fig. 6). Effective rate constants can also be calculated for each subgrid domain (advection domain, macropore diffusion domain, and intra-granular domain, Fig. 9A). The effective rate constants within individual subgrid domains deviate much less from the intrinsic value. The result implied that macroscopic models would improve the prediction by explicitly considering subgrid reactive domains if effective rate constants are unknown, and the intrinsic rate constant is used for model prediction in heterogeneous materials. However, Figure 9A demonstrates that the effective rate constants for individual domains still deviate from the intrinsic value. This deviation is expected to decrease with the application of more subgrid domains, but it cannot be completely eliminated. Model prediction using the intrinsic rate constant will always contain errors regardless how many subgrid domains are considered.

\section{CONCLUSIONS}

Geochemical and biogeochemical reactions occur fundamentally at the pore scale, and they are coupled and modified by transport processes in subsurface materials. These coupled pore-scale processes are, however, below the spatial resolution of most core and field scale observations. Consequently solute and solid phase concentrations and reaction rates observed at the macroscopic scales reflect the manifestation of coupled pore-scale reactions and transport that in most cases cannot be explicitly separated. Pore-scale reactive transport models can theoretically be used to simulate pore-scale processes and their coupling. These models, however, require pore-scale properties that are difficult to obtain for practical problems at the macroscopic scales. Consequently, medium-based reactive transport models with porous media reaction and transport properties defined on a numerical grid volume of porous media have to be adopted based on the mass conservation law. The theoretical analysis and results in this chapter demonstrate that reaction rates and rate constants defined on a numerical grid volume in heterogeneous materials are generally different from the intrinsic reaction rate and rate constants. The effective rate constants for the grid volume depend on the statistical distributions of reactants and their spatial correlation, which are expected to vary with both temporal and spatial scales, causing scale-dependent behavior of effective reaction rates and rate constants. Importantly, the deviation of the effective rate constants from the intrinsic value can be reduced if a macroscopic model considers reactive transport in subgrid domains. The subgrid domains may be derived from non-reactive tracer transport behavior that can be independently measured for a subsurface system at the appropriate scales of interest. However, subgrid domain models cannot completely eliminate the deviation of the effective rate constants from the intrinsic value, and thus contain uncertainty in model prediction.

Other factors beyond pore-scale process coupling can also affect the scaling of reaction rates from the molecular to macroscopic scales in heterogeneous subsurface materials. For example, the reaction rate at the molecular scale can be heterogeneous, even on a single mineral phase (Piana et al. 2006; Spagnoli et al. 2006; Boily and Rosso 2011; Lüttge et al. 2013); the rates of reactions occurring in nano-pores can be influenced by water ordering, 
surface curvature, and overlapping double layers (Kerisit and Liu 2009, 2012; Argyris et al. 2010; Bourg and Steefel 2012); and mineral surface reactivity can be modified as reactions proceed (Alekseyev et al. 1997; Benner et al. 2002; White and Brantley 2003; Bernard 2005; Noiriel et al. 2005; Luquot and Gouze 2009). The pore geometry and connectivity can also be changed by mineral precipitation (Steefel and Lichtner 1994; Davis et al. 2006; Zhang et al. 2010a; Yoon et al. 2012; Fanizza et al. 2013; Boyd et al. 2014) and dissolution (Noiriel et al. 2004, 2005, 2009; Bernard 2005; Flukiger and Bernard 2009; Luquot and Gouze 2009; Kang et al. 2010), microbial growth (Taylor and Jaffe 1990; Nambi et al. 2003; Thullner et al. 2004, 2007; Knutson et al. 2005; Seifert and Engesgaard 2007, 2012; Brovelli et al. 2009; Zhang et al. 2010b; Kirk et al. 2012; Tang et al. 2013) and biomineralization (Zhang and Klapper 2010; Cunningham et al. 2011; Pearce et al. 2012; Phillips et al. 2012; Hommel et al. 2013). These and other factors can be superimposed on each other. The effective rate equation (Eqn. 6), the effective rate constants (Eqn. 7), and the numerical results and data presented in this chapter represent a starting point for a systematic analysis of scale-dependent behavior of geochemical and biogeochemical reactions. Given the ubiquity of heterogeneity in subsurface materials, understanding, predicting, and minimizing the deviation of the effective reaction rate and rate constant from the intrinsic rate and rate constant is critically important in applying mechanism-based kinetic parameters for calibrating and predicting larger scale reactions and reactive transport.

\section{ACKNOWLEDGMENT}

This research is supported by the U.S. DOE, Office of Science, Biological and Environmental Research (BER) as part of the Subsurface Biogeochemical Research (SBR) Program through Pacific Northwest National Laboratory (PNNL) SBR Science Focus Area (SFA) Research Project. This research was performed using Environmental Molecular Science Laboratory (EMSL), a DOE Office of Science user facility sponsored by the DOE's Office of BER and located at PNNL. PNNL is operated for DOE by Battelle Memorial Institute under contract DE-AC05-76RL01830.

\section{REFERENCES}

Acharya RC, Van der Zee S, Leijnse A (2005) Transport modeling of nonlinearly adsorbing solutes in physically heterogeneous pore networks. Water Resour Res 41:W02020

Alekseyev VA, Medvedeva LS, Prisyagina NI, Meshalkin SS, Balabin AI (1997) Change in the dissolution rates of alkali feldspars as a result of secondary mineral precipitation and approach to equilibrium. Geochim Cosmochim Acta 61:1125-1142

Anbeek C (1993) The effect of natural weathering on dissolution rates. Geochim Cosmochim Acta 57:49634975

Anderson SP, Dietrich WE, Brimhall GH (2002) Weathering profiles, mass-balance analysis, and rates of solute loss: Linkages between weathering and erosion in a small, steep catchment. Geol Soc Am Bull 114:1143-1158

Argyris D, Cole DR, Striolo A (2010) Ion-specific effects under confinement: The role of interfacial water. ACS Nano 4:2035-2042

Ball WP, Buehler C, Harmon TC, Mackay DM, Roberts PV (1990) Characterization of a sandy aquifer material at the grain scale. J Contam Hydrol 5:253-295

Ball WP, Roberts PV (1991) Long-term sorption of halogenated organic chemicals by aquifer material. 2. Intraparticle diffusion. Environ Sci Technol 25:1237-1249

Bao C, Wu H, Li L, Newcomer D, Long PE, Williams KH (2014) Uranium bioreduction rates across scales: Biogeochemical hot moments and hot spots during a biostimulation experiment at rifle, Colorado. Environ Sci Technol 48:10116-10127

Barber Ii LB, Thurman EM, Runnells DD (1992) Geochemical heterogeneity in a sand and gravel aquifer: Effect of sediment mineralogy and particle size on the sorption of chlorobenzenes. J Contam Hydrol 9:35-54 
Bear J (1979) Groundwater Hydraulics. McGraw, New York.

Benner SG, Hansel CM, Wielinga BW, Barber TM, Fendorf S (2002) Reductive dissolution and biomineralization of iron hydroxide under dynamic flow conditions. Environ Sci Technol 36:1705-1711

Berkowitz B (2002) Characterizing flow and transport in fractured geological media: A review. Adv Water Resour 25:861-884

Berkowitz B, Scher H (1998) Theory of anomalous chemical transport in random fracture networks. Phys Rev E 57:5858-5869

Bernard D (2005) 3D quantification of pore-scale geometrical changes using synchrotron computed microtomography. Oil Gas Sci Technol 60:747-762

Beven K, Germann P (1982) Macropores and water flow in soils. Water Resour Res 18:1311-1325

Bi E, Zhang L, Schmidt TC, Haderlein SB (2009) Simulation of nonlinear sorption of N-heterocyclic organic contaminates in soil columns. J Contam Hydrol 107:58-65

Bird RB, Stewart WE, Lightfoot EN (2007) Transport Phenomena. John Wiley \& Sons, New York

Boily J-F, Rosso KM (2011) Crystallographic controls on uranyl binding at the quartz/water interface. Phys Chem Chem Phys 13:7845-7851

Bourg IC, Steefel CI (2012) Molecular dynamics simulations of water structure and diffusion in silica nanopores. J Phys Chem C 116:11556-11564

Boyd V, Yoon H, Zhang C, Oostrom M, Hess N, Fouke B, Valocchi AJ, Werth CJ (2014) Influence of $\mathrm{Mg}^{2+}$ on $\mathrm{CaCO}_{3}$ precipitation during subsurface reactive transport in a homogeneous silicon-etched pore network. Geochim Cosmochim Acta 135:321-335

Brovelli A, Malaguerra F, Barry DA (2009) Bioclogging in porous media: Model development and sensitivity to initial conditions. Environ Modell Softw 24:611-626

Brusseau ML, Jessup RE, Rao PSC (1992) Modeling solute transport influenced by multiprocess nonequilibrium and transformation reactions. Water Resour Res 28:175-182

Chandler D (1987) Introduction to Modern Statistical Mechanics. Oxford University Press, Oxford

Chiogna G, Bellin A (2013) Analytical solution for reactive solute transport considering incomplete mixing within a reference elementary volume. Water Resour Res 49:2589-2600

Crank J (1975) The Mathematics of Diffusion, 2nd Edition ed. Clarendon Press, Oxford

Criscenti LJ, Brantley SL, Mueller KT, Tsomaia N, Kubicki JD (2005) Theoretical and ${ }^{27}$ Al CPMAS NMR investigation of aluminum coordination changes during aluminosilicate dissolution. Geochim Cosmochim Acta 69:2205-2220

Criscenti LJ, Kubicki JD, Brantley SL (2006) Silicate glass and mineral dissolution: calculated reaction paths and activation energies for hydrolysis of a $\mathrm{Q}^{3} \mathrm{Si}$ by $\mathrm{H}_{3} \mathrm{O}^{+}$using ab initio methods. J Phys Chem $\mathrm{A}$ 110:198-206

Cunningham AB, Gerlach R, Spangler L, Mitchell AC, Parks S, Phillips A (2011) Reducing the risk of well bore leakage of $\mathrm{CO}_{2}$ using engineered biomineralization barriers. Energy Procedia 4:5178-5185

Dang LX, Annapureddy HVR (2013) Computational studies of water exchange around aqueous $\mathrm{Li}^{+}$with polarizable potential models. J Chem Phys 139:084506

Davis JM, Roy ND, Mozley PS, Hall JS (2006) The effect of carbonate cementation on permeability heterogeneity in fluvial aquifers: An outcrop analog study. Sediment Geol 184:267-280

Dellago C, Bolhuis PG, Csajka FS, Chandler D (1998) Transition path sampling and the calculation of rate constants. J. Chem Phys 108:1964-1977

Dentz M, Le Borgne T, Englert A, Bijeljic B (2011) Mixing, spreading and reaction in heterogeneous media: A brief review. J Contam Hydrol 120-21:1-17

Doudou S, Vaughan DJ, Livens FR, Burton NA (2012) Atomistic simulations of calcium uranyl(VI) carbonate adsorption on calcite and stepped-calcite surfaces. Environ Sci Technol 46:7587-7594

Drot R, Roques J, Simoni E (2007) Molecular approach of the uranyl/mineral interfacial phenomena. CR Chimie 10:1078-1091

Dupin HJ, McCarty PL (2000) Impact of colony morphologies and disinfection on biological clogging in porous media. Environ Sci Technol 34:1513-1520

Dupin HJ, Kitanidis PK, McCarty PL (2001) Pore-scale modeling of biological clogging due to aggregate expansion: A material mechanics approach. Water Resour Res 37:2965-2979

Edery Y, Guadagnini A, Scher H, Berkowitz B (2013) Reactive transport in disordered media: Role of fluctuations in interpretation of laboratory experiments. Adv Water Resour 51:86-103

Ewing RP, Hu Q, Liu C (2010) Scale dependence of intragranular porosity, tortuosity, and diffusivity. Water Resour Res 46:W06513

Ewing RP, Liu C, Hu Q (2012) Modeling intragranular diffusion in low-connectivity granular media. Water Resour Res 48:W03518

Fanizza MF, Yoon H, Zhang C, Oostrom M, Wietsma TW, Hess NJ, Bowden ME, Strathmann TJ, Finneran KT, Werth CJ (2013) Pore-scale evaluation of uranyl phosphate precipitation in a model groundwater system. Water Resour Res 49:84-890 
Flukiger F, Bernard D (2009) A new numerical model for pore-scale dissolution of calcite due to $\mathrm{CO}_{2}$ saturated water flow in 3D realistic geometry: Principles and first results. Chem Geol 265:171-180

Fredd CN, Fogler HS (1998) Influence of transport and reaction on wormhole formation in porous media. AIChE J 44:1933-1949

Fridjonsson EO, Seymour JD, Schultz LN, Gerlach R, Cunningham AB, Codd SL (2011) NMR measurement of hydrodynamic dispersion in porous media subject to biofilm mediated precipitation reactions. J Contam Hydrol 120-21:79-88

Geckeis H, Lützenkirchen J, Polly R, Rabung T, Schmidt M (2013) Mineral-water interface reactions of actinides. Chem Rev 113:1016-1062

Gharasoo M, Centler F, Regnier P, Harms H, Thullner M (2012) A reactive transport modeling approach to simulate biogeochemical processes in pore structures with pore-scale heterogeneities. Environ Modell Softw 30:102-114

Ginn TR (2009) Generalization of the multirate basis for time convolution to unequal forward and reverse rates and connection to reactions with memory. Water Resour Res 45:W12419

Glezakou V-A, deJong WA (2011) Cluster-models for uranyl(VI) adsorption on $\alpha$-alumina. J Phys Chem A 115:1257-1263

Greathouse JA, Cygan RT (2005) Molecular dynamics simulation of uranyl(VI) adsorption equilibria onto an external montmorillonite Surface. Phys Chem Chem Phys 7:3580-3586

Greathouse JA, Cygan RT (2006) Water structure and aqueous uranyl(VI) adsorption equilibria onto external surfaces of beidellite, montmorillonite, and pyrophyllite: Results from molecular simulations. Environ Sci Technol 40:3865-3871

Greathouse JA, O'Brien RJ, Bemis G, Pabalan RT (2002) Molecular dynamics study of aqueous uranyl interactions with quartz (010). J Phys Chem B 106:1646-1655

Greathouse JA, Stellalevinsohn HR, Denecke MA, Bauer A, Pabalan RT (2005) Uranyl surface complexes in a mixed-charge montmorillonite: Monte Carlo computer simulation and polarized XAFS results. Clays Clay Miner 53:278-286

Haggerty R, Gorelick SM (1995) Multiple-rate mass transfer for modeling diffusion and surface reactions in media with pore-scale heterogeneity. Water Resour Res 31:2383-2400

Harrison J, Maranger R, Alexander R, Giblin A, Jacinthe P-A, Mayorga E, Seitzinger S, Sobota D, Wollheim W (2009) The regional and global significance of nitrogen removal in lakes and reservoirs. Biogeochem 93:143-157

Hattori T, Saito T, Ishida K, Scheinost AC, Tsuneda T, Nagasaki S, Tanaka S (2009) The structure of monomeric and dimeric uranyl adsorption complexes on gibbsite: A combined DFT and EXAFS study. Geochim Cosmochim Acta 73:5975-5988

Hay MB, Stoliker DL, Davis JA, Zachara JM (2011) Characterization of the intragranular water regime within subsurface sediments: Pore volume, surface area, and mass transfer limitations. Water Resour Res 47:W10531

Hommel J, Cunningham AB, Helmig R, Ebigbo A, Class H (2013) Numerical investigation of microbially induced calcite precipitation as a leakage mitigation technology. Energy Procedia 40:392-397

Huber C, Shafei B, Parmigiani A (2014) A new pore-scale model for linear and non-linear heterogeneous dissolution and precipitation. Geochim Cosmochim Acta 124:109-130

Hurlimann MD, Helmer KG, Latour LL, Sotak CH (1994) Restricted diffusion in sedimentary rocks. Determination of surface-area-to-volume ratio and surface relaxivity. J Magn Reson Ser A 111:169-178

Kang Q, Lichtner PC, Zhang D (2006) Lattice Boltzmann pore-scale model for multicomponent reactive transport in porous media. J Geophys Res-Solid Earth 111:B05203

Kang Q, Lichtner PC, Viswanathan HS, Abdel-Fattah AI (2010) Pore-scale modeling of reactive transport involved in geologic $\mathrm{CO}_{2}$ sequestration. Transp Porous Media 82:197-213

Kang Q, Chen L, Valocchi AJ, Viswanathan HS (2014) Pore-scale study of dissolution-induced changes in permeability and porosity of porous media. J Hydrol 517:1049-1055

Kerisit S, Liu C (2009) Molecular Simulations of Water and Ion Diffusion in Nanosized Mineral Fractures. Environ Sci Technol 43:777-782

Kerisit S, Liu C (2012) Diffusion and Adsorption of Uranyl Carbonate Species in Nanosized Mineral Fractures. Environ Sci Technol 46:1632-1640

Kerisit S, Liu C (2013) Structure, kinetics, and thermodynamics of the aqueous uranyl(VI) cation. J Phys Chem A 117:6421-6432

Kerisit S, Liu C (2014) Molecular dynamics simulations of uranyl and uranyl carbonate adsorption at aluminosilicate surfaces. Environ Sci Technol 48:3899-3907

Kerisit S, Parker SC (2004a) Free energy of adsorption of water and calcium on the $\{10 \overline{1} 4\}$ calcite surface. Chem Comm 1:52-53

Kerisit S, Parker SC (2004b) Free energy of adsorption of water and metal ions on the $\{10 \overline{1} 4\}$ calcite surface. J Am Chem Soc 126:10152-10161 
Kerisit S, Rosso KM (2009) Transition path sampling of water exchange rates and mechanisms around aqueous ions. J. Chem Phys 131:114512

Kessler AJ, Cardenas MB, Santos IR, Cook PLM (2014) Enhancement of denitrification in permeable carbonate sediment due to intra-granular porosity: A multi-scale modelling analysis. Geochim Cosmochim Acta 141:440-453

Kirk MF, Santillan EFU, McGrath LK, Altman SJ (2012) Variation in hydraulic conductivity with decreasing $\mathrm{pH}$ in a biologically-clogged porous medium. Int J Greenhouse Gas Control 11:133-140

Knutson CE, Werth CJ, Valocchi AJ (2005) Pore-scale simulation of biomass growth along the transverse mixing zone of a model two-dimensional porous medium. Water Resour Res 41:W07007

Knutson C, Valocchi A, Werth C (2007) Comparison of continuum and pore-scale models of nutrient biodegradation under transverse mixing conditions. Adv Water Resour 30:1421-1431

Kremleva A, Krüger S, Rösch N (2008) Density functional model studies of uranyl adsorption on (001) surfaces of kaolinite. Langmuir 24:9515-9524

Kremleva A, Krüger S, Rösch N (2010) Quantum chemical modeling of uranyl adsorption on mineral surfaces. Radiochim Acta 98:635-646

Kremleva A, Krüger S, Rösch N (2011) Uranyl adsorption at (010) edge surfaces of kaolinite: A density functional study. Geochim Cosmochim Acta 75:706-718

Kremleva A, Martorell B, Krüger S, Rösch N (2012) Uranyl adsorption onsolvated edge surfaces of pyrophyllite: a DFT model study. Phys Chem Chem Phys 14:5815-5823

Laio A, Parrinello M (2002) Escaping free-energy minima. Proc Natl Acad Sci 99:12552-12556

Lasaga AC (1979) The treatment of multi-component diffusion and ion pairs in diagenetic fluxes. Am J Sci 279:324-346

Lectez S, Roques J, Salanne M, Simoni E (2012) Car-parrinello molecular dynamics study of the uranyl behaviour at the Gibbsite/water interface. J. Chem Phys 137:154705

Lee MR, Hodson ME, Parsons I (1998) The role of intragranular microtextures and microstructures in chemical and mechanical weathering: direct comparisons of experimentally and naturally weathered alkali feldspars. Geochim Cosmochim Acta 62:2771-2788

Li L, Peters CA, Celia MA (2006) Upscaling geochemical reaction rates using pore-scale network modeling. Adv Water Resour 29:1351-1370

Li L, Peters CA, Celia MA (2007) Applicability of averaged concentrations in determining geochemical reaction rates in heterogeneous porous media. Am J Sci 307:1146-1166

Li L, Steefel CI, Yang L (2008) Scale dependence of mineral dissolution rates within single pores and fractures. Geochim Cosmochim Acta 72:360-377

Li L, Gawande N, Kowalsky MB, Steefel CI, Hubbard SS (2011) Physicochemical heterogeneity controls on uranium bioreduction rates at the field scale. Environ Sci Technol 45:9959-9966

Lichtner PC, Kang Q (2007) Upscaling pore-scale reactive transport equations using a multiscale continuum formulation. Water Resour Res 43:W12S15

Liu C, Zachara JM, Yantasee W, Majors PD, McKinley JP (2006) Microscopic reactive diffusion of uranium in the contaminated sediments at Hanford, United States. Water Resour Res 42:W12420

Liu C, Zachara JM, Foster NS, Strickland J (2007) Kinetics of reductive dissolution of hematite by bioreduced anthraquinone-2,6-disulfonate. Environ Sci Technol 41:7730-7735

Liu C, Zachara JM, Qafoku NP, Wang Z (2008) Scale-dependent desorption of uranium from contaminated subsurface sediments. Water Resour Res 44:W08413

Liu C, Shang J, Zachara JM (2011) Multispecies diffusion models: A study of uranyl species diffusion. Water Resour Res 47:W12514

Liu C, Shang J, Kerisit S, Zachara JM, Zhu W (2013a) Scale-dependent rates of uranyl surface complexation reaction in sediments. Geochim Cosmochim Acta 105:326-341

Liu X-Y, Wang L-H, Zheng Z, Kang M-L, Li C, Liu C-L (2013b) Molecular dynamics simulation of the diffusion of uranium species in clay pores. J Hazard Mater 244-245:21-28

Liu C, Shang J, Shan H, Zachara JM (2014a) Effect of subgrid heterogeneity on scaling geochemical and biogeochemical reactions: A case of U(VI) desorption. Environ Sci Technol 48:1745-1752

Liu Y, Liu C, Zhang C, Yang X, Zachara JM (2015) Pore and continuum scale study of the effect of subgrid transport heterogeneity on redox reaction rates. Geochim Cosmochim Acta 163:140-155

Loeffler HH, Inada Y, Funahashi S (2006) Water exchange dynamics of lithium(I) ion in aqueous solution. J Phys Chem B 110:5690-5696

Luquot L, Gouze P (2009) Experimental determination of porosity and permeability changes induced by injection of $\mathrm{CO}_{2}$ into carbonate rocks. Chem Geol 265:148-159

Luquot L, Rodriguez O, Gouze P (2014) Experimental characterization of porosity structure and transport property changes in limestone undergoing different dissolution regimes. Transp Porous Media 101:507532 
Lüttge A, Arvidson RS, Fischer C (2013) A stochastic treatment of crystal dissolution kinetics. Elements 9:183-188

Ma R, Zheng C, Liu C, Greskowiak J, Prommer H, Zachara JM (2014) Assessment of controlling processes for field-scale uranium reactive transport under highly transient flow conditions. Water Resour Res 50:10061024

Maher K (2010) The dependence of chemical weathering rates on fluid residence time. Earth Planet Sci Lett 294:101-110

Malmström ME, Destouni G, Banwart SA, Strömberg BHE (2000) Resolving the scale-dependence of mineral weathering rates. Environ Sci Technol 34:1375-1378

Malmström ME, Destouni G, Martinet P (2004) Modeling expected solute concentration in randomly heterogeneous flow systems with multicomponent reactions. Environ Sci Technol 38:2673-2679

Marsili E, Baron DB, Shikhare ID, Coursolle D, Gralnick JA, Bond DR (2008) Shewanella Secretes flavins that mediate extracellular electron transfer. Proc Natl Acad Sci 105:3968-3973

Martorell B, Kremleva A, Krüger S, Rösch N (2010) Density functional model study of uranyl adsorption on the solvated (001) surface of kaolinite. J Phys Chem C 114:13287-13294

McGreavy C, Andrade JS, Rajagopal K (1992) Consistent evaluation of effective diffusion and reaction in pore networks. Chem Eng Sci 47:2751-2756

McKinley JP, Zachara JM, Liu C, Heald SC, Prenitzer BI, Kempshall BW (2006) Microscale controls on the fate of contaminant uranium in the vadose zone, Hanford Site, Washington. Geochim Cosmochim Acta 70:1873-1887

McKinley JP, Zachara JM, Wan J, McCready DE, Heald SM (2007) Geochemical controls on contaminant uranium in vadose Hanford formation sediments at the 200 Area and 300 Area, Hanford site. Vadose Zone J 6:1004-1017

Mehmani Y, Sun T, Balhoff MT, Eichhubl P, Bryant S (2012) Multiblock pore-scale modeling and upscaling of reactive transport: Application to carbon sequestration. Transp Porous Media 95:305-326

Meile C, Tuncay K (2006) Scale dependence of reaction rates in porous media. Adv Water Resour 29:62-71

Miller AW, Rodriguez DR, Honeyman BD (2010) Upscaling sorption/desorption processes in reactive transport models to describe metal/radionuclide transport: A critical review. Environ Sci Technol 44:7996-8007

Mo ZM, Friedly JC (2000) Local reaction and diffusion in porous media transport models. Water Resour Res 36:431-438

Molins S, Mayer KU, Amos RT, Bekins BA (2010) Vadose zone attenuation of organic compounds at a crude oil spill site - Interactions between biogeochemical reactions and multicomponent gas transport. J Contam Hydrol 112:15-29

Molins S, Trebotich D, Steefel CI, Shen C (2012) An investigation of the effect of pore-scale flow on average geochemical reaction rates using direct numerical simulation. Water Resour Res 48:W03527

Molins S, Trebotich D, Yang L, Ajo-Franklin JB, Ligocki TJ, Shen C, Steefel CI (2014) Pore-scale controls on calcite dissolution rates from flow-through laboratory and numerical experiments. Environ Sci Technol 48:7453-7460

Morrow CP, Kubicki JD, Mueller KT, Cole DR (2010) Description of $\mathrm{Mg}^{2+}$ release from forsterite using ab initio methods. J Phys Chem C 114:5417-5428

Moskaleva LV, Krüger S, Spörl A, Rösch N (2004) Role of solvation in the reduction of the uranyl dication by water: A density functional study. Inorg Chem 43:4080-4090

Nambi IM, Werth CJ, Sanford RA, Valocchi AJ (2003) Pore-scale analysis of anaerobic halorespiring bacterial growth along the transverse mixing zone of an etched silicon pore network. Environ Sci Technol 37:5617-5624

Navarre-Sitchler A, Brantley S (2007) Basalt weathering across scales. Earth Planet Sci Lett 261:321-334

Navarre-Sitchler A, Steefel CI, Yang L, Tomutsa L, Brantley SL (2009) Evolution of porosity and diffusivity associated with chemical weathering of a basalt clast. J Geophys Res Earth Surf 114:F02016

Noiriel C, Gouze P, Bernard D (2004) Investigation of porosity and permeability effects from microstructure changes during limestone dissolution. Geophys Res Lett 31:L24603

Noiriel C, Bernard D, Gouze P, Thibault X (2005) Hydraulic properties and microgeometry evolution accompanying limestone dissolution by acidic water. Oil Gas Sci Technol 60:177-192

Noiriel C, Luquot L, Made B, Raimbault L, Gouze P, van der Lee J (2009) Changes in reactive surface area during limestone dissolution: An experimental and modelling study. Chem Geol 265:160-170

Noiriel C, Steefel CI, Yang L, Ajo-Franklin J (2012) Upscaling calcium carbonate precipitation rates from pore to continuum scale. Chem Geol 318:60-74

Orgogozo L, Golfier F, Bues M, Quintard M (2010) Upscaling of transport processes in porous media with biofilms in non-equilibrium conditions. Adv Water Resour 33:585-600

Pallud C, Kausch M, Fendorf S, Meile C (2010a) Spatial patterns and modeling of reductive ferrihydrite transformation observed in artificial soil aggregates. Environ Sci Technol 44:74-79 
Pallud C, Masue-Slowey Y, Fendorf S (2010b) Aggregate-scale spatial heterogeneity in reductive transformation of ferrihydrite resulting from coupled biogeochemical and physical processes. Geochim Cosmochim Acta 74:2811-2825

Pan Q-J, Odoh SO, Asaduzzaman AM, Schreckenbach G (2012) Adsorption of uranyl species onto the rutile (110) surface: A periodic DFT study. Chem Eur J 18:1458-1466

Panga MKR, Ziauddin M, Balakotaiah V (2005) Two-scale continuum model for simulation of wormholes in carbonate acidization. AIChE J 51:3231-3248

Patsahan T, Holovko M (2007) Molecular dynamics study of aqueous uranyl in hydrophilic mesoporous confinement: the case of slit-like pore in amorphous silica. Condens Matter Phys 10:143-150

Pearce CI, Wilkins MJ, Zhang C, Heald SM, Fredrickson JK, Zachara JM (2012) Pore-scale characterization of biogeochemical controls on iron and uranium speciation under flow conditions. Environ Sci Technol 46:7992-8000

Perron H, Domain C, Roques J, Drot R, Simoni E, Catalette H (2006a) Periodic density functional theory investigation of the uranyl ion sorption on the $\mathrm{TiO}_{2}$ rutile (110) face. Inorg Chem 45:6568-6570

Perron H, Domain C, Roques J, Drot R, Simoni E, Catalette H (2006b) Theoretical first step towards an understanding of the uranyl ion sorption on the rutile $\mathrm{TiO}_{2}(110)$ face: A DFT periodic and cluster study. Radiochim Acta 94:601-607

Perron H, Roques J, Domain C, Drot R, Simoni E, Catalette H (2008) Theoretical investigation of the uranyl ion sorption on the rutle $\mathrm{TiO}_{2}$ (110) face. Inorg Chem 47:10991-10997

Phillips AJ, Lauchnor E, Eldring J, Esposito R, Mitchell AC, Gerlach R, Cunningham AB, Spangler LH (2012) Potential $\mathrm{CO}_{2}$ leakage reduction through biofilm-induced calcium carbonate precipitation. Environ Sci Technol 47:142-149

Piana S, Jones F, Gale JD (2006) Assisted desolvation as a key kinetic step for crystal growth. J Am Chem Soc 2006:13568-13574

Porta GM, Riva M, Guadagnini A (2012) Upscaling solute transport in porous media in the presence of an irreversible bimolecular reaction. Adv Water Resour 35:151-162

Porta GM, Chaynikov S, Thovert J-F, Riva M, Guadagnini A, Adler PM (2013) Numerical investigation of pore and continuum scale formulations of bimolecular reactive transport in porous media. Adv Water Resour 62:243-253

Poudel DD, Lee T, Srinivasan R, Abbaspour K, Jeong CY (2013) Assessment of seasonal and spatial variation of surface water quality, identification of factors associated with water quality variability, and the modeling of critical nonpoint source pollution areas in an agricultural watershed. J Soil Water Conserv 68:155-171

Press WH, Teukolsky SA, Vetterling WT, Flannery BP (1992) Numerical Recipes In C: The Art of Scientific Computing, 2nd ed. Cambridge University Press, Cambridge, UK

Qafoku NP, Zachara JM, Liu CX, Gassman PL, Qafoku OS, Smith SC (2005) Kinetic desorption and sorption of U(VI) during reactive transport in a contaminated Hanford sediment. Environ Sci Technol 39:31573165

Raiteri P, Gale JD (2010) Water is key to nonclassical nucleation of amorphous calcium carbonate. J Am Chem Soc 132:17623-17634

Raiteri P, Gale JD, Quigley D, Rodger PM (2010) Derivation of an accurate force-field for simulating the frowth of calcium carbonate from aqueous solution: A new model for the calcite-water interface. J Phys Chem C 114:5997-6010

Raoof A, Nick HM, Hassanizadeh SM, Spiers CJ (2013) PoreFlow: A complex pore-network model for simulation of reactive transport in variably saturated porous media. Comput Geosci 61:160-174

Rey R, Guardia E (1992) Dynamical aspects of the $\mathrm{Na}^{+}-\mathrm{Cl}^{-}$ion pair association in water. J Phys Chem 96:4712-4718

Rey R, Hynes JT (1996a) Hydration shell exchange dynamics for $\mathrm{Na}^{+}$in water. J Phys: Condens Matter 8:9411-9416

Rey R, Hynes JT (1996b) Hydration shell exchange kinetics: an MD study for $\mathrm{Na}^{+}(\mathrm{aq})$. J Phys Chem 100:56115615

Roques J, Veilly E, Simoni E (2009) Periodic density functional theory investigation of the uranyl ion sorption on three mineral surfaces: A comparative study. Int J Mol Sci 10:2633-2661

Rustad JR, Stack AG (2006) Molecular dynamics calculation of the activation volume for water exchange on $\mathrm{Li}^{+}$. J Am Chem Soc 128:14778-14779

Salehikhoo F, Li L, Brantley SL (2013) Magnesite dissolution rates at different spatial scales: The role of mineral spatial distribution and flow velocity. Geochim Cosmochim Acta 108:91-106

Scheibe TD, Fang Y, Murray CJ, Roden EE, Chen J, Chien Y-J, Brooks SC, Hubbard SS (2006) Transport and biogeochemical reaction of metals in a physically and chemically heterogeneous aquifer. Geosphere 2:220-235

Sebbari K, Roques J, Simoni E, Domain C, Perron H, Catalette H (2012) First-principles molecular dynamics simulations of uranyl ion interaction at the water/rutile $\mathrm{TiO}_{2}$ (110) interface. Surf Sci 606:1135-1141 
Seifert D, Engesgaard P (2007) Use of tracer tests to investigate changes in flow and transport properties due to bioclogging of porous media. J Contam Hydrol 93:58-71

Seifert D, Engesgaard P (2012) Sand box experiments with bioclogging of porous media: Hydraulic conductivity reductions. J Contam Hydrol 136-137:1-9

Shang J, Liu C, Wang Z, Zachara JM (2011) Effect of grain size on uranium (VI) surface complexation kinetics and adsorption additivity. Environ Sci Technol 45:6025-6031

Shang J, Liu C, Wang Z, Zachara J (2014) Long-term kinetics of uranyl desorption from sediments under advective conditions. Water Resour Res 50:855-870

Sherman DM, Peacock CL, Hubbard CG (2008) Surface complexation of U(VI) on goethite $(\alpha-\mathrm{FeOOH})$. Geochim Cosmochim Acta 72:298-310

Shi Z, Zachara JM, Shi L, Wang Z, Moore DA, Kennedy DW, Fredrickson JK (2012) Redox reactions of reduced flavin mononucleotide (FMN), riboflavin (RBF), and anthraquinone-2, 6-disulfonate (AQDS) with ferrihydrite and lepidocrocite. Environ Sci Technol 46:11644-11652

Šimunek J, Jarvis NJ, van Genuchten MT, Gärdenäs A (2003) Review and comparison of models for describing non-equilibrium and preferential flow and transport in the vadose zone. J Hydrol 272:14-35

Skomurski FN, Ilton ES, Engelhard MH, Arey BW, Rosso KM (2011) Heterogeneous reduction of $\mathrm{U}^{6+}$ by structural $\mathrm{Fe}^{2+}$ from theory and experiment. Geochim Cosmochim Acta 75:7277-7290

Spagnoli D, Kerisit S, Parker SC (2006) Atomistic simulation of the free energies of dissolution of ions from flat and stepped calcite surfaces. J Cryst Growth 294:103-110

Spångberg D, Rey R, Hynes JT, Hermansson K (2003) Rate and mechanisms for water exchange around $\mathrm{Li}^{+}(\mathrm{aq})$ from MD simulations. J Phys Chem B 107:4470-4477

Stack AG, Rustad JR (2007) Structure and dynamics of water on aqueous barium ion and the $\{001\}$ barite surface. J Phys Chem C 111:16387-16391

Stack AG, Raiteri P, Gale JD (2012) Accurate rates of the complex mechanisms for growth and dissolution of minerals using a combination of rare-event theories. J Am Chem Soc 134:11-14

Stack AG, Gale JD, Raiteri P (2013) Virtual probes of mineral-water interfaces: The more flops, the better! Elements 9:211-216

Steefel CI, Lichtner PC (1994) Diffusion and reaction in rock matrix bordering a hyperalkaline fluid-filled fracture. Geochim Cosmochim Acta 58:3595-3612

Steefel CI, Maher K (2009) Fluid-rock interaction: A reactive transport approach. Rev Mineral Geochem 70:485-532

Steefel CI, Molins S, Trebotich D (2013) Pore-scale processes associated with subsurface $\mathrm{CO}_{2}$ injection and sequestration. Rev Mineral Geochem 77:259-303

Steele HM, Wright K, Hillier IH (2002) Modelling the adsorption of uranyl on the surface of goethite. Geochim Cosmochim Acta 66:1305-1310

Swoboda-Colberg NG, Drever JI (1993) Mineral dissolution rates in plot-scale field and laboratory experiments. Chem Geol 105:51-69

Tan X, Ren X, Li J, Wang X (2013) Theoretical investigation of uranyl ion adsorption on hydroxylated $\gamma-\mathrm{Al}_{2} \mathrm{O}_{3}$ surfaces. RSC Advances 3:19551-19559

Tang Y, Valocchi AJ, Werth CJ, Liu H (2013) An improved pore-scale biofilm model and comparison with a microfluidic flow cell experiment. Water Resour Res 49:8370-8382

Tartakovsky AM, Redden G, Lichtner PC, Scheibe TD, Meakin P (2008a) Mixing-induced precipitation: Experimental study and multiscale numerical analysis. Water Resour Res 44:W06S04.

Tartakovsky AM, Tartakovsky DM, Scheibe TD, Meakin P (2008b) Hybrid simulations of reaction-diffusion systems in porous media. SIAM J Sci Comput 30:2799-2816

Tartakovsky GD, Tartakovsky AM, Scheibe TD, Fang Y, Mahadevan R, Lovley DR (2013) Pore-scale simulation of microbial growth using a genome-scale metabolic model: Implications for Darcy-scale reactive transport. Adv Water Resour 59:256-270

Taylor SW, Jaffe PR (1990) Biofilm growth and the related changes in the physical properties of a porous medium. 1. Experimental investigation. Water Resour Res 26:2153-2159

Teich-McGoldrick SL, Greathouse JA, Cygan RT (2014) Molecular dynamics simulations of uranyl adsorption and structure on the basal surface of muscovite. Mol Sim 40:610-617

Thullner M, Schroth MH, Zeyer J, Kinzelbach W (2004) Modeling of a microbial growth experiment with bioclogging in a two-dimensional saturated porous media flow field. J Contam Hydrol 70:37-62

Thullner M, Regnier P, Van Cappellen P (2007) Modeling microbially induced carbon degradation in redoxstratified subsurface environments: Concepts and open questions. Geomicrobiol J 24:139-155

Trebotich D, Adams MF, Molins S, Steefel CI, Shen C (2014) High-resolution simulation of pore-scale reactive transport processes associated with carbon sequestration. Comput Sci Eng 16:22-31

Tribello GA, Bruneval F, Liew C-C, Parrinello M (2009) A molecular dynamics study of the early stages of calcium carbonate growth. J Phys Chem B 113:11680-11687 
van Duijn CJ, Pop IS (2004) Crystal dissolution and precipitation in porous media: pore-scale analysis. J Reine Angew Math 577:171-211

van Duijn CJ, Pop IS (2005) A microscopic description of crystal dissolution and precipitation, In: Huyghe, JM, Raats, PAC, Cowin, SC (eds) IUTAM Symposium on Physicochemical and Electromechanical Interactions in Porous Media. Springer, p 343-348

Varloteaux C, Bekri S, Adler PM (2013) Pore network modelling to determine the transport properties in presence of a reactive fluid: From pore to reservoir scale. Adv Water Resour 53:87-100

Veilly E, Roques J, Jodin-Caumon M-C, Humbert B, Drot R, Simoni E (2008) Uranyl interaction with the hydrated (001) basal face of gibbsite: A combined theoretical and spectroscopic study. J Chem Phys 129:244704

White AF (1995) Chemical weathering rates of silicate minerals in soils. Rev Mineral Geochem 31:407-461

White AF, Brantley SL (2003) The effect of time on the weathering of silicate minerals: why do weathering rates differ in the laboratory and field? Chem Geol 202:479-506

White AF, Bullen TD, Schulz MS, Blum AE, Huntington TG, Peters NE (2001) Differential rates of feldspar weathering in granitic regoliths. Geochim Cosmochim Acta 65:847-869

Willingham TW, Werth CJ, Valocchi AJ (2008) Evaluation of the effects of porous media structure on mixingcontrolled reactions using pore-scale modeling and micromodel experiments. Environ Sci Technol 42:3185-3193

Yang W, Zaoui A (2013a) Behind adhesion of uranyl onto montmorillonite surface: A molecular dynamics study. J Hazard Mater 26:224-234

Yang W, Zaoui A (2013b) Uranyl adsorption on (001) surfaces of kaolinite: A molecular dynamics study. Appl Clay Sci 80-81:98-106

Yang X, Liu C, Shang J, Fang Y, Bailey VL (2014) A unified multiscale model for pore-scale flow simulations in soils. Soil Sci Soc Am J 78:108-118

Yeh G-T, Tripathi VS (1991) A Model for simulating transport of reactive multispecies components: Model development and demonstration. Water Resour Res 27:3075-3094

Yoon H, Valocchi AJ, Werth CJ, Dewers T (2012) Pore-scale simulation of mixing-induced calcium carbonate precipitation and dissolution in a microfluidic pore network. Water Resour Res 48:W02524

Zachara JM, Kukkadapu RK, Gassman PL, Dohnalkova A, Fredrickson JK, Anderson T (2004) Biogeochemical transformation of Fe minerals in a petroleum-contaminated aquifer. Geochim Cosmochim Acta 68:17911805

Zaidan OF, Greathouse JA, Pabalan RT (2003) Monte Carlo and molecular dynamics simulation of uranyl adsorption on montmorillonite clay. Clays Clay Miner 51:372-381

Zhang T, Klapper I (2010) Mathematical model of biofilm induced calcite precipitation. Water Sci Technol 61:2957-2964

Zhang X, Lv M (2009) The nonlinear adsorptive kinetics of solute transport in soil does not change with porewater velocity: Demonstration with pore-scale simulations. J Hydrol 371:42-52

Zhang X, Crawford JW, Young LM (2008) Does pore water velocity affect the reaction rates of adsorptive solute transport in soils? Demonstration with pore-scale modelling. Adv Water Resour 31:425-437

Zhang C, Dehoff K, Hess N, Oostrom M, Wietsma TW, Valocchi AJ, Fouke BW, Werth CJ (2010a) Porescale study of transverse mixing induced $\mathrm{CaCO}_{3}$ precipitation and permeability reduction in a model subsurface sedimentary system. Environ Sci Technol 44:7833-7838

Zhang C, Kang Q, Wang X, Zilles JL, Müller RH, Werth CJ (2010b) Effects of pore-scale heterogeneity and transverse mixing on bacterial growth in porous media. Environ Sci Technol 44:3085-3092

Zhang X, Qi X, Qiao D (2010c) Change in macroscopic concentration at the interface between different materials: Continuous or discontinuous. Water Resour Res 46:W10540

Zhang C, Liu C, Shi Z (2013a) Micromodel investigation of transport effect on the kinetics of reductive dissolution of hematite. Environ Sci Technol 47:4131-4139

Zhang X, Jiang B, Zhang X (2013b) Reliability of the multiple-rate adsorptive model for simulating adsorptive solute transport in soil demonstrated by pore-scale simulations. Transp Porous Media 98:725-741

Zinn B, Harvey CF (2003) When good statistical models of aquifer heterogeneity go bad: A comparison of flow, dispersion, and mass transfer in connected and multivariate Gaussian hydraulic conductivity fields. Water Resour Res 39:SBH 1-4 